\title{
MOVILIDAD INTERGENERACIONAL Y GASTO PUBLICO EN ARGENTINA*
}

\author{
INTERGENERATIONAL MOBILITY AND PUBLIC SPENDING IN \\ ARGENTINA
}

\section{MARIBEL JIMENEZ** \\ Consejo Nacional de Investigaciones Científicas y Técnicas (CONICET)}

\begin{abstract}
The main objective of this article is to determine the effect of public spending on intergenerational socioeconomic mobility (MI) in Argentina. Also analyzes their impact on the mobility gap observed between children from different socioeconomic backgrounds family. The identification strategy used is to exploit the temporal variability of public spending. The results suggest that public spending increases MI. This effect is higher when spending categories most directly related to the human capital of children and adolescents are increased. But the magnitudes of the estimated effects are modest.
\end{abstract}

Keywords: Intergenerational mobility, income, education, public spending, mobility gap, investment in human capital, childhood, Argentina.

JEL Classification: J62, D31, I38.

\section{Resumen}

El principal objetivo de este artículo es determinar el efecto que tiene el gasto público sobre la movilidad socioeconómica intergeneracional (MI) en Argentina. Asimismo se analiza su impacto respecto de la brecha de

* Agradezco a Leonardo Gasparini por sus valiosos comentarios y observaciones. También agradezco las sugerencias realizadas por el Comité de Doctorado, por los asistentes a los Seminarios de Doctorado de la Universidad Nacional de La Plata y por Ana Inés Navarro en la XLVII Reunión Anual de la AAEP que han enriquecido versiones preliminares de este artículo.

** Consejo Nacional de Investigaciones Científicas y Técnicas (CONICET), Instituto de Estudios Laborales y del Desarrollo Económico (IELDE), Universidad Nacional de Salta (UNSa).

E-mail: jimenmar@gmail.com, maribeljimenez@conicet.gov.ar 
movilidad observada entre los hijos de distintos entornos socioeconómicos familiares. La estrategia de identificación empleada consiste en explotar la variabilidad temporal del gasto público. Los resultados obtenidos sugieren que el gasto público aumenta la MI. Este efecto es mayor cuando se incrementan las categorías del gasto más directamente relacionadas con el capital humano de los niños y adolescentes. Pero las magnitudes de los efectos estimados son modestas.

Palabras clave: Movilidad intergeneracional, ingresos, educación, gasto público, brecha de movilidad, inversión en capital humano, niñez, Argentina.

Clasificación JEL: J62, D31, I38.

\section{INTRODUCCION}

En los últimos años la mayoría de la literatura acerca de movilidad intergeneracional (MI), particularmente la que analiza la MI del ingreso (MII), se ha concentrado en obtener una medida adecuada del nivel de MI, siendo relativamente más escasas las investigaciones que avanzaron en la identificación de los factores causales subyacentes al proceso de transmisión del ingreso entre generaciones. Sin embargo, comprender los mecanismos subyacentes a las correlaciones intergeneracionales es crucial para el desarrollo de políticas públicas apropiadas que promuevan el objetivo social relevante en materia de equidad. Por esto, un estudio de la transmisión intergeneracional del ingreso y de sus determinantes puede aportar información útil para el diseño de políticas adecuadas.

Según los modelos teóricos que analizan los factores asociados con la MII (Mulligan, 1997; Solon, 2004; Ichino, Karabarbounis y Moretti, 2011 ${ }^{1}$ ), no solo la inversión de los padres en sus hijos es uno de los principales canales de transmisión intergeneracional de ingresos, sino también la inversión del gobierno en el capital humano de los niños y adolescentes. Así, el modelo de Mulligan (1997) muestra que los hijos de familias favorecidas con subsidios estatales pueden beneficiarse de los recursos adicionales ofrecidos por el programa social. Sin embargo, este puede afectar la formación del altruismo intergeneracional de los padres y en la medida

1 Ichino, Karabarbounis y Moretti (2011) proponen un modelo teórico que incorpora endógenamente las inversiones públicas en capital humano. Este esquema teórico muestra que la MII en cualquier sociedad puede estar influenciada por las preocupaciones e intereses en la política económica. Así, las sociedades donde las familias mejor posicionadas económicamente tienen una mayor influencia en el proceso político, tenderán a tener menores inversiones redistributivas en el capital humano y, por tanto, mayores niveles de persistencia intergeneracional. Según estos autores, contrariamente a lo que se asume en general, una baja correlación entre el ingreso paterno y el de los hijos no es siempre deseable, pues puede implicar más ineficiencia debido a los efectos distorsionadores de las políticas públicas dirigidas a incrementar la movilidad. Además, tomando en cuenta la heterogeneidad en las preferencias por la movilidad intergeneracional, llegan a la conclusión de que incluso si una sociedad completamente móvil es deseable ex ante, puede no ser políticamente sustentable ex post. 
en que las acciones públicas a favor de los niños se financian con impuestos, su efecto neto depende de la forma en que se introducen esos impuestos. Un modelo teórico que se destaca en el contexto de esta investigación es el desarrollado por Solon (2004), que extiende el modelo seminal de Becker y Tomes (1979) ${ }^{2}$ al incluir el efecto de la inversión pública en el capital humano de los niños. Específicamente el modelo muestra que cuanto más progresiva sea esta inversión del gobierno -en el sentido de que la ratio entre inversión pública e ingreso de los padres disminuya con el ingreso parental- mayor será la MII, ceteris paribus. A partir del modelo de Becker y Tomes (1979) puede derivarse también un marco teórico para comprender los determinantes de los logros educativos de los hijos y cómo las acciones del gobierno pueden afectar las correlaciones educativas intergeneracionales. La política pública en gran medida define las elecciones educativas disponibles para padres e hijos, afectando el acceso legal y práctico a la escolaridad, así como la calidad y costos de la educación. De esta manera, las acciones del gobierno pueden modificar la oferta y la demanda de educación ${ }^{3}$ (Behrman, Gaviria y Székeley, 2001). Las decisiones políticas también pueden cambiar el retorno económico de la educación y de otras formas de inversiones del hogar en el capital humano de los hijos. Los padres entonces determinan las inversiones de tiempo y dinero que realizan en la educación de sus hijos considerando sus restricciones presupuestarias ${ }^{4}$. Los hijos, por su parte, toman decisiones respecto del esfuerzo educativo que realizarán en función, entre otros factores, de los costos y beneficios percibidos que, a su vez, dependen en parte de las percepciones de las condiciones existentes en el mercado laboral (Hertz, Meurs y Selckuk, 2009).

Atendiendo a ese marco teórico, el principal objetivo de esta investigación es determinar el efecto que tiene sobre la MII en Argentina el gasto público, concretamente el realizado por los tres niveles de gobiernos (nacional, provincial y municipal) que pueden modificar las inversiones públicas en el capital humano de los niños y adolescentes. Específicamente, se busca evaluar si el gasto público cumple con uno de los objetivos centrales de la política social que es incrementar la movilidad económica intergeneracional y la igualdad de oportunidades, disminuyendo el impacto del origen socioeconómico en el ingreso obtenido en la adultez. Asimismo, se pretende examinar si la brecha de movilidad observada entre los hijos que provienen de distintos entornos

2 Becker y Tomes (1979) desarrollaron el modelo económico original concerniente a movilidad intergeneracional del ingreso basado en la idea de que cada familia maximiza una función de utilidad que incorpora el bienestar de varias generaciones. En este esquema el ingreso de los hijos depende de las inversiones que realizan sus padres en ellos y de las denominadas "dotaciones" que reciben ya sean determinadas genéticamente, como la raza, la habilidad y otras características, así como aquellas conformadas por las conexiones familiares y los valores o conocimientos dados por el entorno familiar.

3 Así, por ejemplo, el incremento del gasto público en educación o en capital humano, en general y las mejoras en la calidad de las escuelas públicas son medidas que tienen un impacto en el lado de la oferta. En tanto que las acciones gubernamentales que reducen las restricciones financieras que enfrentan los hogares para invertir en capital humano impactan en la demanda educativa (Behrman, Gaviria y Székeley).

4 El acceso al mercado crediticio puede afectar también esta decisión, principalmente en los niveles de educación más elevados. 
socioeconómicos familiares es menor para aquellos que experimentaron mayores niveles de gasto público durante su adolescencia.

Los estudios empíricos que examinan la relación entre movilidad intergeneracional y gasto público son escasos a nivel internacional, y prácticamente inexistentes a nivel nacional. Entre los antecedentes más directos de esta investigación se encuentran los estudios de Mayer y Lopoo (ML) (2008) para Estados Unidos y de Behrman, Gaviria y Székeley (BGS) (2001) para 19 países latinoamericanos y Estados Unidos 5 . En el primero, ML utilizando los datos del Panel Study of Income Dynamics (PSID) encuentran que la persistencia intergeneracional del ingreso (medida a partir de la elasticidad intergeneracional del ingreso ${ }^{6}$ ) es mayor en los estados de Estados Unidos con un menor gasto por niño que en aquellos que presentan un mayor nivel de gasto público. La estrategia de identificación se basa, principalmente, en el cambio temporal observado en los niveles de gasto público por niño ${ }^{7}$. Como el modelo empírico incluye efectos fijos por el estado en el que residían los hijos cuando tenían 15 años, las estimaciones obtenidas no surgen de la variación crosssection en los niveles de gasto entre los estados. El estudio de BGS, por su parte, examina los efectos del gasto público en educación como porcentaje del PBI sobre el índice de correlación educativa propuesto por Dahan y Gaviria (2001) ${ }^{8}$ para 19 países latinoamericanos y Estados Unidos. La estrategia de identificación está basada en un modelo de panel con efectos fijos por país. Los resultados obtenidos sugieren que dedicar más recursos a la educación pública incrementa la movilidad intergeneracional. No obstante, si bien el método de efectos fijos elimina el sesgo potencial de factores inobservables invariantes en el tiempo, las estimaciones podrían aún estar sesgadas por la presencia de características omitidas de los países que varían en el tiempo y están correlacionadas con el gasto público así como con el índice de movilidad educativa.

A diferencia de los dos estudios previos que se concentran en una medida de posición socioeconómica, el ingreso, en el caso del primero, y la educación, en el caso del segundo, en esta investigación se examina el efecto del gasto público tanto en la MII como en la MI educativa (MIE). La variable educación presenta varias ventajas sobre los ingresos en términos de estimación, especialmente en países como Argentina con falta de información de largo plazo para generaciones sucesivas de una misma familia. Esto genera mayores problemas de estimación

5 Otros estudios relacionados con esta investigación, aunque no tan directamente, son los que analizan el efecto de cambios en políticas públicas respecto de los niveles de movilidad intergeneracional. Así, Mulligan (1997), Machin (2007) y Pekkarinen, Uusitalo y Kerr (2009) examinan la relación entre las políticas educativas y la movilidad del ingreso entre generaciones. Los estudios que exploran los efectos de las políticas públicas sobre la movilidad educativa intergeneracional son escasos pero crecientes. Entre ellos se mencionan los de Lillard y Willis (1994), Deng y Treiman (1997), Duflo (2001), Hertz y Jayasundera (2007) y Hertz, Meurs y Selckuk (2009).

6 En la próxima sección se define esta medida de MII.

7 Los autores computan el gasto público por niño en cada año dividiendo los gastos totales por la población de 0 a 17 años existente en cada estado, en cada año. Luego promedian este gasto estatal por niño durante los 3 años en los que los hijos adultos tenían entre 15 a 17 años.

8 Este índice está basado en la correlación de la escolaridad entre hermanos y mide el grado con el que sus resultados educativos pueden ser explicados por el trasfondo familiar. 
cuando la variable de resultado utilizada es el ingreso, porque el análisis de la MII requiere observar el ingreso de padres e hijos en momentos similares de sus ciclos vitales, preferentemente en sus edades centrales. Si bien existen métodos, como la técnica Two-Sample Instrumental Variable (TSIV), implementada en esta investigación, que pueden aliviar estos inconvenientes ${ }^{9}$, los supuestos en los que se basa la consistencia de las estimaciones así obtenidas podrían resultar demasiado restrictivos. Además, el examen de la MIE es de interés en sí mismo, porque los logros educativos ofrecen una fuente importante de información acerca del estatus y bienestar socioeconómico de los individuos. De esta forma, el análisis de la correlación entre la educación de padres e hijos constituye una alternativa informativa y factible al análisis basado en el ingreso para examinar la transmisión socioeconómica intergeneracional (Hertz, Meurs y Selckuk, 2009). Además, a diferencia de los estudios mencionados que solo analizan el efecto del gasto total (en el caso de ML) o del gasto en educación (en el caso de BGS), en esta investigación se consideran distintas categorías y agregados del gasto público consolidado (GPC), particularmente del gasto público social, con el objetivo de explorar el efecto que diferentes medidas de la inversión pública en el capital humano de niños y adolescentes tienen en la movilidad intergeneracional.

Por otra parte, la estrategia de identificación empleada en esta investigación se basa fundamentalmente en explotar la variabilidad temporal del gasto público, de forma similar a como lo hacen ML y BGS. Sin embargo, a diferencia de estos estudios, en los modelos estimados se incluyen, además de efectos fijos locales, un amplio conjunto de variables de control a nivel local que capturan características variables en el tiempo (o entre cohortes) potencialmente relacionadas con el gasto público y con las variables de resultados (ingresos y educación) como, por ejemplo, la recaudación tributaria provincial y la carga tributaria nacional. Si no se incluyeran estos controles por provincia, cualquier diferencia en la movilidad intergeneracional por niveles de gasto podría ser parcialmente endógena, entre otras razones, porque, a causa de la misma tasa de impuestos, los cambios en los ingresos de los residentes en una provincia se podrían traducir en cambios en la recaudación y en el gasto público. También se incluyen controles por otras características provinciales que varían no solo localmente, sino también en el tiempo, como, por ejemplo, la tasa de pobreza por Necesidades básicas insatisfechas (NBI), el nivel de desigualdad o la tasa de mortalidad infantil existente en la provincia de residencia de cada hijo adulto cuando era adolescente o joven. Estos controles resultan relevantes porque algunas categorías de gasto público, particularmente del gasto público social, se ajustan a los cambios en las necesidades existentes, de manera que las provincias con más familias pobres tenderán a gastar más que las provincias con menos familias pobres. La omisión de estas variables de control podrían sesgar las estimaciones del término de interacción entre la posición socioeconómica de los padres y el gasto público que captura el efecto que este último tiene en las medidas de persistencia intergeneracional consideradas.

9 En la Sección 2 se describe esta técnica de estimación. 
Con relación a los estudios sobre movilidad intergeneracional en Argentina se debe señalar que la mayoría no examina la movilidad del ingreso sino la movilidad ocupacional o educativa entre generaciones ${ }^{10}$. Además ninguno de los artículos revisados se propone examinar los efectos del gasto público sobre la MI, el que constituye el principal objetivo de esta investigación.

Los resultados obtenidos sugieren que el gasto público tiene el efecto esperado, incrementando la movilidad intergeneracional tanto del ingreso como la educativa. Sin embargo, no todas las categorías de gasto son igualmente efectivas para conseguir este resultado. Así, se observa una disminución mayor en la persistencia socioeconómica entre generaciones cuando se incrementan las categorías del GPC más directamente relacionadas con el capital humano de los niños y adolescentes como el gasto en salud y educación.

Este artículo está organizado de la siguiente manera. En la Sección 2 se analizan el modelo empírico, el método de estimación y la estrategia de identificación utilizada para examinar la relación entre movilidad intergeneracional y gasto público. La Sección 3 contiene una descripción de las fuentes de datos utilizadas. En la Sección 4 se presentan y analizan los resultados obtenidos, para terminar, luego, en la última sección, con las principales conclusiones de la investigación.

\section{METODOLOGIA}

El modelo empírico tradicional considerado en la literatura para medir el grado de persistencia socioeconómica promedio entre generaciones es el siguiente:

$$
y_{h i}=\beta y_{p i}+\varepsilon_{h i}
$$

donde $y_{h i}$ y $y_{p i}$ son medidas de la posición socioeconómica de hijos y padres, respectivamente. Cuando se considera como medida de estatus económico el ingreso, entonces el modelo intergeneracional (1) relaciona el logaritmo del ingreso permanente de hijos y padres, siendo $\beta$ la elasticidad intergeneracional del ingreso (EII), esto es, una medida del grado de persistencia del ingreso permanente de padres e hijos. En tanto que, cuando la educación se utiliza como medida de posición socioeconómica, el modelo (1) relaciona los años de educación de los hijos con el de los padres, siendo $\beta$ en este caso un coeficiente que mide la persistencia educativa intergeneracional (CPE en adelante). Este modelo asume implícitamente que la variable utilizada para medir la posición socioeconómica del padre capturará el efecto directo de esta en la posición del hijo, así como el impacto de factores omitidos correlacionados con ambas como características y atributos genéticos de los padres (o la educación del padre en el caso del modelo de MII). Por tanto, ni la EII ni el CPE constituyen (ni se espera que sean) una medida del efecto causal de la posición socioeconómica de los

10 En Jiménez (2011) puede consultarse una revisión de los estudios sobre movilidad socioeconómica intergeneracional en Argentina. 
padres en el resultado económico de los hijos considerado en cada caso. En general, es inevitable que ambos indicadores sobrestimen cualquier relación causal que exista como resultado de la correlación entre el ingreso o la educación de los padres y otras variables explicativas en la ecuación estructural del resultado económico de los hijos. No obstante, aun así, la EII y la CPE constituyen medidas relevantes y ampliamente utilizadas de inmovilidad intergeneracional.

Debido a que el objetivo de esta investigación es examinar cómo el gasto público afecta la EII, el modelo a estimar es el siguiente:

$$
\begin{aligned}
Y_{h i, c j t}= & \alpha+\beta Y_{p i, c j}+\delta_{1} G_{c j}+\delta_{2}\left(Y_{p i, c j} \times G_{c j}\right)+\gamma A_{i c j}+\theta X_{c j} \\
& +\phi D_{j}+\pi D_{t}+\vartheta\left(D_{t} \times D_{j}\right)+\lambda D_{c}+\varepsilon_{i c j t}
\end{aligned}
$$

donde $c$ indexa la cohorte de nacimiento, $j$ la provincia de residencia, y $t$ el año, $Y_{h i, c j t}$ y $Y_{p i, c j}$ son las variables que miden la posición socioeconómica del hijo y padre (el logaritmo del ingreso familiar, en el modelo de MII o los años de educación, en el modelo MIE); $G_{c j}$ es el logaritmo del gasto público per cápita experimentado por la cohorte $c$ en una etapa determinada de su ciclo de vida (se obtiene como el gasto público per cápita promedio durante los años $t$ en que los individuos de cada cohorte eran adolescentes o jóvenes); $A_{i c j}$ son controles individuales que incluyen el sexo del hijo, un polinomio de grado cuarto en su edad y en la edad del padre; $X_{c j}$ es un vector de variables de control a nivel provincial que varían por cohorte y en la especificación más completa del modelo incluye los recursos tributarios provinciales, la carga tributaria nacional por provincia, la tasa de desocupación, el nivel de desigualdad medido por el coeficiente de Gini, la tasa de crecimiento del Producto Bruto Geográfico (PBG), la tasa de pobreza por NBI, la tasa de asistencia a cada nivel educativo, los años de educación promedio de la población en edad de trabajar (PET), la cantidad total de población, la proporción de la población sin cobertura de salud, la tasa de mortalidad infantil (por mil nacidos vivos), la tasa de mortalidad total (por mil habitantes), el porcentaje de la población sin acceso a agua corriente y sin acceso a desagües cloacales, el partido político del gobernador de cada provincia en relación con el del presidente al mando ${ }^{11} \mathrm{y}$, cuando se considera el gasto público en alguna categoría particular, se incluye como variable de control la proporción del gasto destinada al resto de las categorías no consideradas; $D_{j}$ es un conjunto de dummies por provincia de residencia (efectos fijos por lugar); $D_{t}$ son dummies por año (efectos fijos por año), $D_{c}$ son dummies por cohorte de nacimiento (efectos fijos por cohorte) y $D_{t} \times D_{j}$ es el término de interacción entre las dummies locales y temporales que se introduce para capturar posibles tendencias específicas por provincia en el ingreso de los hijos que podrían estar correlacionadas con los cambios ocurridos en el gasto público. El coeficiente de interés, en este caso, es $\delta_{2}$, que corresponde al término de interacción

11 La variable incluida indica para cada hijo adulto la proporción de años durante su adolescencia o juventud en los que el gobernador de su provincia fue del mismo partido que el presidente al mando. En la Sección 4 se presenta una breve justificación de su inclusión como variable de control. 
entre el ingreso parental y el gasto público y captura el efecto de este último sobre la EII. Es importante destacar que la incorporación de efectos fijos por provincia implica que la estrategia de identificación subyacente al modelo (2) se basa, principalmente, en el cambio temporal (por cohorte de nacimiento) observado en los niveles de gasto público consolidado per cápita y no en la variación cross-section de los niveles de gasto entre las provincias.

Como es probable que, a pesar de los efectos fijos por provincia, por cohorte y por año, los controles por las características de padres e hijos así como por características socioeconómicas de las provincias incluidas en el modelo (2), existan factores inobservables omitidos que pueden segar el efecto estimado del gasto público sobre la movilidad intergeneracional, se implementa otra estrategia de identificación propuesta por ML. Esta técnica consiste en explorar el efecto del gasto público consolidado en la movilidad intergeneracional utilizando un enfoque de diferencias en diferencias. Específicamente se asume que la "brecha de movilidad" entre hijos que provienen de un trasfondo familiar aventajado y aquellos que no están en esta situación, es menor en las provincias con un elevado gasto público consolidado per cápita que en aquellas con un bajo gasto público. Entonces, si el GPC incrementa la movilidad global es probable que lo haga aumentando más la movilidad de los hijos más desventajados en términos socioeconómicos que la de aquellos más aventajados, ya que este es, o se espera que sea, uno de los principales objetivos del gasto público, particularmente del gasto público social. Para testear esta hipótesis se estima el siguiente modelo:

$$
\begin{aligned}
Y_{h i, c j t}= & \alpha+\beta Y_{p i, c j}+\delta_{1} E_{p i, c j}+\delta_{2}\left(Y_{p i, c j} \times E_{p, j c}\right)+\gamma A_{i c j}+\theta X_{c j} \\
& +\phi D_{j}+\pi D_{t}+\vartheta\left(D_{t} \times D_{j}\right)+\lambda D_{c}+v_{c j}+\omega_{i c j t}
\end{aligned}
$$

donde $E_{p i, c j}$ es una variable dummy igual a uno si el nivel educativo de los padres es igual o menor al secundario completo -con esto se intenta identificar a los hijos que provienen de un trasfondo familiar desventajado o no-, $\omega_{c j t}$ es un término de error estocástico y $v_{c j}$ captura los factores omitidos inobservables que podrían sesgar los coeficientes estimados de interés $\delta_{1}$ y $\delta_{2}$, se asume que el efecto de estos factores inobservables es el mismo entre los hijos que experimentaron distintos niveles de gasto público per cápita en su provincia de residencia. Entonces, bajo este supuesto, al computar la diferencia en las diferencias del coeficiente $\delta_{2}$ se obtendrían estimaciones insesgadas del efecto del gasto público en las brechas de movilidad entre hijos de padres con baja y alta educación.

Un problema que se presenta para estimar los modelos (1), (2) ó (3) y, en general, la movilidad intergeneracional en países como Argentina es la falta de información de largo plazo para generaciones sucesivas de una misma familia. Una forma de solucionar este problema es implementando una estrategia de estimación con variables instrumentales utilizando dos muestras, una principal en la que se observa el ingreso de los hijos y ciertas características de los padres (educación, ocupación, 
ubicación geográfica) y una muestra auxiliar de un momento en el pasado en el que los padres eran más jóvenes. Basados en la segunda muestra es posible predecir el ingreso de los padres en el pasado a partir de los parámetros estimados en la muestra auxiliar y de las características observadas de los padres en la muestra principal. Esos ingresos predichos son usados en la segunda etapa del procedimiento como regresores del modelo de ingresos de los hijos, estimado con la primera muestra ${ }^{12}$.

En esta investigación, como en la mayoría de los estudios empíricos previos que analizan la movilidad intergeneracional del ingreso combinando dos conjuntos de datos diferentes, la elección de los instrumentos está limitada por la escasa información disponible. En función de ella, se emplea como variable instrumental la educación del padre ${ }^{13}$. Sin embargo, si la educación del padre pertenece como regresor al modelo estructural del ingreso permanente del hijo, bajo supuestos plausibles ${ }^{14}$, esto ocasionaría una sobrestimación de la EII. En este caso, se podría pensar que nuestras estimaciones ofrecen un límite superior de la EII ${ }^{15}$.

En comparación con la MII, el análisis de la movilidad intergeneracional educativa presenta menos problemas de medición. En efecto, la educación tiene varias ventajas como variable de resultado respecto de los ingresos en términos de estimación. Así, los individuos tienden a completar su educación a mediados de los 20 años, entonces el análisis se puede realizar cuando los hijos son relativamente más jóvenes. En cambio, según el análisis del Haider y Solon (2006), para medir MII es conveniente medir el ingreso de padres e hijos en las edades centrales de su ciclo vital para evitar el denominado life-cycle bias ${ }^{16}$. Asimismo, el error de medición es probablemente un problema menor cuando se utiliza la educación porque las personas informan con mayor precisión su educación (o la de sus padres) que sus ingresos. Además, una gran cantidad de estudios muestran que la educación está asociada positivamente con otros indicadores de bienestar socioeconómico como los ingresos, la salud y la esperanza de vida (Black y Deveraux, 2011).

Por otra parte, la estimación del grado de MI puede estar sesgada cuando se emplean, como en esta investigación, muestras de padres e hijos corresidentes ${ }^{17}$. La selección por corresidencia surge cuando se observan solamente los ingresos

12 Para más detalles acerca de ese método (conocido como TSIV), ver Jiménez (2011).

13 Numerosos estudios que intentan estimar la EII con el método TSIV utilizaron la educación del padre como instrumento (Solon, 1992; Lillard y Kilburn, 1995; Núñez y Risco, 2004; Núñez y Miranda, 2011; entre otros).

14 Estos supuestos son analizados formalmente en Jiménez (2016).

15 Pero si en línea con los hallazgos de Corcoran et al. (1992) y Mazumder (2005), el efecto directo de la educación del padre sobre el ingreso del hijo no es estadísticamente distinto de cero, una vez que se controla por el ingreso del padre promediado durante varios años, la estimación por IV y TSIV de la EII sería consistente.

16 Estas y otras cuestiones metodológicas relacionadas con la medición de la movilidad intergeneracional del ingreso se discuten formalmente en Jiménez (2016).

17 Pocos estudios de movilidad intergeneracional analizan este sesgo de selección muestral, entre ellos se pueden mencionar los de Couch y Lillard (1998), Mazumder (2005), Nicoletti y Francesconi (2006) y Nicoletti (2008). 
de hijos y padres que viven juntos y no se dispone de información de los padres que no residen con sus hijos (Nicoletti y Francesconi, 2006). Si la submuestra de individuos observados que residen con sus padres no es aleatoria, entonces la selección por corresidencia puede causar un sesgo en la estimación de la movilidad intergeneracional y llevar a una subrepresentación de los ingresos reales de hijos adultos porque los que continúan viviendo con sus padres probablemente son aún estudiantes o no tienen ingresos suficientes para vivir independientemente. Si se asume que los hijos emancipados tienen, en promedio, mayores ingresos que los residentes con sus padres y provienen de una familia rica, la movilidad estimada sería mayor que la verdadera al no poder incluir estas familias en la muestra. Por el contrario, si aquellos provienen de una familia pobre, la movilidad intergeneracional computada sería menor que la verdadera. Un resultado similar resulta de suponer que los hijos emancipados son pobres. La dirección del sesgo no es, pues, tan clara (Sánchez Hugalde, 2004). No obstante, cuando se compararon las estimaciones de la EII computadas para Argentina con una muestra de padres e hijos corresidentes, obtenidas de la EPH, con las derivadas utilizando una muestra libre de este sesgo, obtenida de la Encuesta de Percepción de Planes Sociales del 2007 (EPPS), los resultados alcanzados con ambas muestras son similares, las estimaciones no presentan diferencias estadísticamente significativas y sugieren que este problema no las afecta considerablemente. Además, si este sesgo de selección es el mismo para los hijos corresidentes que experimentaron distintos niveles de gasto público en su niñez o adolescencia, entonces la técnica de diferencias en diferencias eliminaría su efecto del coeficiente de interés.

\section{DATOS}

Como el principal objetivo de esta investigación es determinar el efecto que tiene en la movilidad intergeneracional de ingresos el gasto público, las fuentes de información empleadas son varias. En primer lugar se utilizaron los microdatos obtenidos de la Encuesta Permanente de Hogares (EPH) para el período 1998-2012. Además se emplearon los datos del gasto público consolidado (GPC) distribuido por jurisdicción ${ }^{18}$ y desagregado por finalidad y función disponibles para el período 1998-2008 que provienen de la Dirección de Análisis del Gasto Público y Programas Sociales (DAGPyPS) del Ministerio de Economía y Finanzas Públicas de la Nación (MECON). El cómputo del GPC incluye las erogaciones del sector público no financiero correspondientes a los tres niveles de gobierno-nación, provincias y Ciudad Autónoma de Buenos Aires (CABA) y municipios. También se utilizaron

18 En el Anexo B se describe el método implementado para realizar esta distribución así como el proceso de consolidación del gasto. 
las series históricas de varios indicadores provinciales como variables de control obtenidos de distintas fuentes de información ${ }^{19}$.

La muestra principal incluye a hijos adultos de 25 a 34 años que nacieron entre 1978 y 1987 con ingresos familiares per cápita positivos y proviene de la EPH en su modalidad continua para el período $2003-2012^{20}$. La elección del rango etario para los hijos así como del año inicial del período analizado responde a varias razones, entre ellas, las limitaciones informativas relacionadas con la falta de disponibilidad de datos del gasto público consolidado provincial por finalidad y función para años previos a 1998 y el método de estimación implementado para estimar el ingreso paterno en la adolescencia o juventud de los hijos. Como la EPH no contiene información concerniente al ingreso de los padres cuando los hijos eran más jóvenes ${ }^{21}$, con el fin de predecir el ingreso familiar en la adolescencia de los hijos se emplea otra muestra anterior obtenida de los datos de la EPH relevada en un año previo al de la muestra principal, comprendido en el período 1998-2008, según la cohorte de nacimiento de cada hijo. La elección de estos años -así como del rango etario para los hijos- obedece a varias razones. En primer lugar, se asume, siguiendo a Núñez y Miranda (2011) y Núñez y Risco (2004), que los padres toman las principales decisiones de inversiones en el capital humano de sus hijos cuando estos son niños y adolescentes ${ }^{22}$. Estas inversiones constituyen una de las principales fuentes de transmisión socioeconómica entre generaciones. Se utiliza como medida de los recursos familiares disponibles para realizar estas inversiones un promedio del ingreso familiar per cápita paterno estimado cuando los hijos tenían menos de 24 años $^{23}$. Los individuos que tienen entre 25 y 34 años en el período 2003-2012, tenían 24 años o menos, en algún año del período 1998-2008, según su cohorte de nacimiento (ver Cuadro A1). En segundo lugar, la ampliación del rango de edad de los hijos implicaría emplear datos de la EPH de años anteriores

19 Para más detalles, ver Anexo B.

20 Para obtener una muestra anual de hijos adultos a partir de cada EPH, se unieron las observaciones correspondientes a los distintos relevamientos realizados dentro del año (dos, en la EPHP y cuatro, en la EPHC), pero dado que la encuesta tiene la estructura de un panel corto de datos y en cada relevamiento la muestra se renueva en un determinado porcentaje, se eliminaron las observaciones repetidas, dejando una observación para cada individuo en cada año a fin de no sesgar los resultados.

21 La encuesta no incluye preguntas retrospectivas sobre el ingreso de los padres en un momento en el pasado del ciclo de vida de los hijos y tiene la estructura de un panel corto de datos.

22 Behrman y Taubman (1990) reportan que la persistencia de ingresos es mayor cuando los padres son observados durante los años de escolaridad de los hijos antes que en un momento posterior de su ciclo de vida.

23 Así, por ejemplo, para estimar el ingreso promedio del padre para la cohorte de hijos adultos del año 1984 que tiene 28 años en 2012 se utilizaron las muestras secundarias obtenidas de la EPH para el período 1999 a 2008, años en los que los hijos de la muestra principal tenían entre 15 y 24 años. Estas muestras secundarias están conformada por individuos adultos varones que tienen de 25 a 55 años y además son padres de hijos de la misma cohorte de nacimiento que los hijos adultos de la muestra principal. A partir de estas muestras auxiliares se estiman los retornos de la educación de los padres en cada año del período 1998-2008. Estos retornos se utilizan luego para computar el ingreso predicho que el padre de cada hijo adulto de la muestra principal obtenía, en promedio, en función de su educación. 
al considerado para cada cohorte, con el fin de predecir el ingreso paterno en su adolescencia y juventud. Pero en este caso la cantidad de aglomerados cubiertos por la encuesta se reduciría ${ }^{24}$.

Los datos del gasto público consolidado (GPC) por provincia y por finalidad y función solo están disponibles desde 1998. Con el fin de utilizar una medida de la inversión pública en el capital humano de los hijos durante el mismo período en que se mide la inversión privada realizada por los padres en sus hijos y en la misma etapa del ciclo de vida para todas las cohortes, se utiliza como proxy de esa inversión pública, el gasto público consolidado per cápita ${ }^{25}$ (GPCpc) promediado cuando los adultos de la muestra principal tenían entre 18 y 24 años ${ }^{26}$ (ver Cuadro A1). Como advierten ML, como indicador de inversión, el gasto público comparte las mismas limitaciones que el ingreso familiar como proxy de la inversión parental. Así, las provincias que gastan la misma cantidad podrían comprar diferentes bienes y tener distintos niveles de eficiencia en sus compras dependiendo de una variedad de circunstancias. No obstante, algunas categorías del GPC como el gasto social, el gasto en educación, en atención de la salud, cuyos efectos individuales respecto de la movilidad intergeneracional se examinan en esta investigación, se podrían considerar como medidas menos imperfectas de la inversión pública en distintos aspectos configurativos del capital humano de los niños y adolescentes que habitan cada provincia.

Debe advertirse también que, como la EPH recolecta información solo de los centros urbanos más importantes del país en términos de tamaño de población, las muestras son representativas de las ciudades pero no de toda la población nacional. Esto puede llevar a una sobrestimación de la movilidad generacional en el país porque la muestra considerada no representa grupos de la población para quienes se espera que la persistencia generacional de ingresos sea mayor, como aquellos que viven en áreas rurales o pequeños centros urbanos (Núñez y Miranda, 2011). No obstante, en Argentina un elevado porcentaje de la población total habita en centros urbanos, por lo tanto la EPH representa aproximadamente el $70 \%$ de la población urbana y el $60 \%$ de la población total del país.

24 Los aglomerados cubiertos por las EPH desde 1998 hasta el 2012 (en una o ambas ondas de la EPH en su modalidad puntual) son 29. Por tanto, se cuenta con al menos un aglomerado de todas las provincias argentinas, con excepción de Río Negro (cuyo aglomerado Viedma-Carmen de Patagones se incorporó a la EPH en 2002).

25 El gasto público per cápita se computa como el cociente entre el gasto público consolidado correspondiente a cada provincia y la población provincial total en cada año.

26 Se advierte que se asume, por falta de información, que los hijos adultos de la muestra principal residen en la misma provincia en que habitaron durante su juventud. Claramente, este supuesto no se cumple en caso de los que migraron después y no retornaron a la provincia en la que vivieron entre los 18 y 24 años. Sin embargo, según los datos de la EPH, el porcentaje promedio de los individuos de la muestra que nacieron en otra provincia o país es $8,7 \%$ y el porcentaje promedio que realizó una migración internacional o entre provincias en los últimos 5 años es $0,6 \%$. Y la eliminación de estos individuos de la muestra no modifica sustancialmente los resultados obtenidos. 


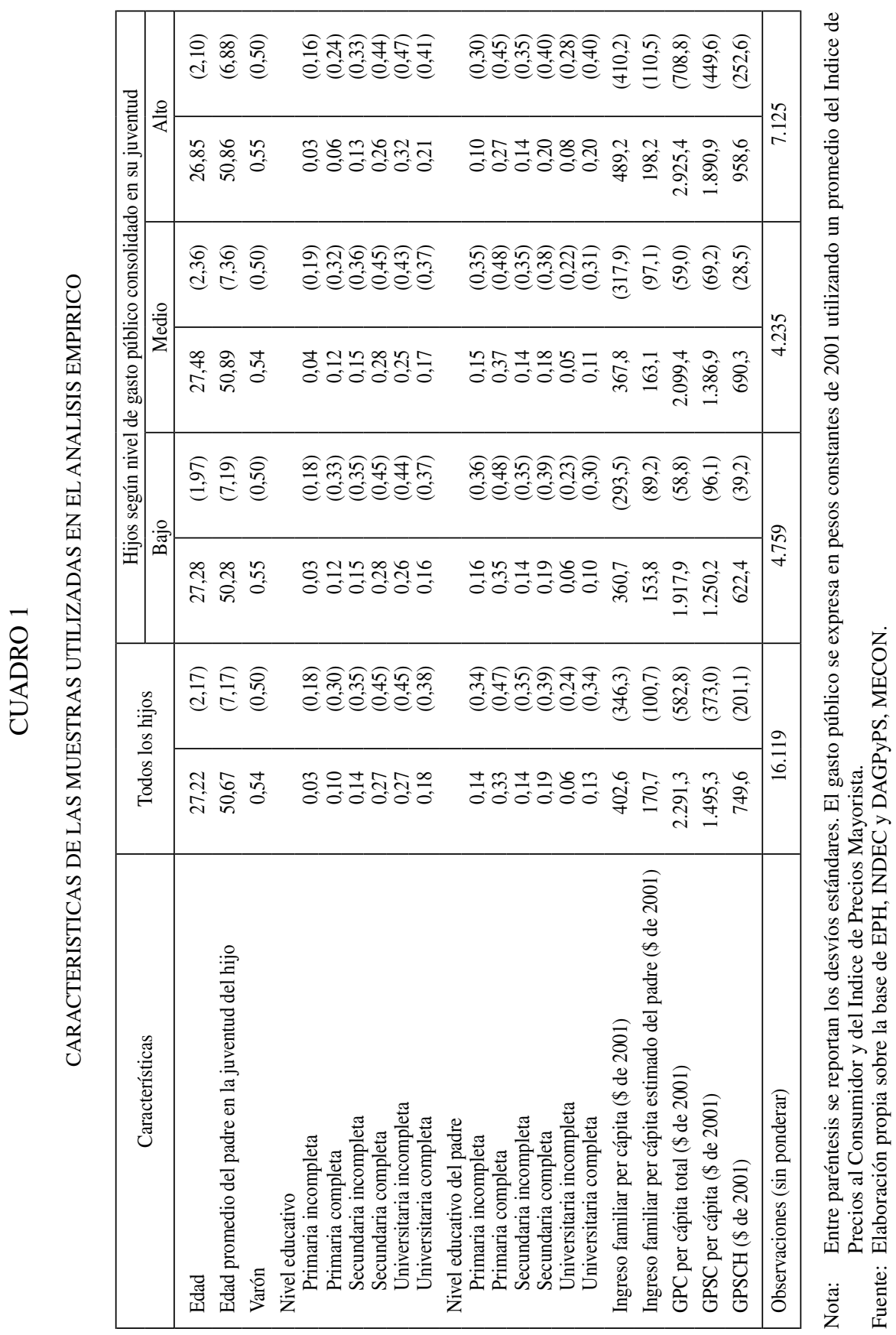


En el Cuadro 1 se reportan algunas características de las muestras de hijos utilizadas en el análisis empírico. La primera columna corresponde a la muestra total de hijos de 25 a 34 años que habitaban con sus padres en algún año del período 2003-2012. En las columnas siguientes se observan las características para las tres muestras de hijos construidas según el nivel promedio de gasto público consolidado que experimentaron durante su adolescencia y juventud. La clasificación de los niveles de gasto en bajo, medio y alto surge de dividir en tres partes la distribución del gasto público consolidado per cápita promedio en la juventud de cada hijo adulto incluido en la muestra principal.

En el análisis empírico siguiente las estimaciones se realizaron utilizando un agregado del gasto público social consolidado per cápita que puede tener un efecto más directo en el capital humano de hijos (GPSCH). Esta medida incluye el gasto público social consolidado per cápita en salud, promoción y asistencia social y educación total. También se consideraron distintas categorías y subcategorías del gasto público social consolidado per cápita (GPSCpc): el gasto público en educación total, en educación básica, en educación superior, en cultura, en salud total, en atención de la salud y obras sociales $^{27}$, en agua potable y alcantarillado, vivienda y urbanismo, en promoción y asistencia social, en previsión social y en programas de empleo.

\section{RESULTADOS}

\subsection{Efecto del gasto público en la movilidad intergeneracional}

En el Cuadro 2 se observan las elasticidades intergeneracionales del ingreso y los coeficientes de persistencia educativa obtenidos a partir de la estimación de distintas especificaciones del modelo (1) utilizando el método TSIV en el caso de la EII y el método de OLS para el CPE. Los índices de persistencia socioeconómica intergeneracional son estadísticamente significativos a un nivel del $1 \%$ y no presentan variaciones considerables entre las distintas especificaciones. La EII promedio a nivel nacional para el período 2003-2012 e hijos de 25 a 39 años varía de 0.65 a 0,70, mientras que el CPE tiene valores entre 0,38 y 0,39 según los controles incluidos en el modelo estimado.

27 La incorporación de la categoría "obras sociales" como gasto público merece una aclaración metodológica. La DAGPyPS del MECON justifica su inclusión por varias razones, entre ellas, por considerar que su figura jurídica, creada por ley especial de la Nación, no se rige por la legislación general para personas jurídicas de carácter civil o comercial. Además, las obras sociales son entidades que proporcionan servicios de salud, turismo y asistencia social a sus afiliados y son financiadas con impuestos sobre la nómina salarial, contribuciones patronales y aportes de los trabajadores. Asimismo, se debe destacar el carácter solidario del seguro. Por último, la contabilización de este seguro social como gasto público es convalidada por la metodología internacional, típicamente la del Fondo Monetario Internacional (DAGPyPS, 2009). 


\section{CUADRO 2}

MEDIDAS DE PERSISTENCIA INTERGENERACIONAL. 2003-2012

\begin{tabular}{|c|c|c|c|}
\hline Medida de MI & Modelo 1 & Modelo 2 & Modelo 3 \\
\hline Elasticidad intergeneracional del ingreso & $\begin{array}{c}0,701 * * * \\
(0,042)\end{array}$ & $\begin{array}{c}0,648^{* * *} \\
(0,013)\end{array}$ & $\begin{array}{c}0,648^{* * * *} \\
(0,011)\end{array}$ \\
\hline Coeficiente de persistencia educativa & $\begin{array}{c}0,392^{* * *} \\
(0,007)\end{array}$ & $\begin{array}{c}0,392^{* * *} \\
(0,014)\end{array}$ & $\begin{array}{c}0,379 * * * \\
(0,013)\end{array}$ \\
\hline
\end{tabular}

Nota: $\quad * * * p$-value $<0,01, * * p$-value $<0,05, * p$-value $<0,1$. Entre paréntesis se reportan los errores estándares agrupados a nivel provincial. El Modelo 1 incluye además del logaritmo del ingreso predicho del padre, controles por el sexo y la edad del hijo y de los padres (polinomio cuártico); el Modelo 2, incluye además de las variables anteriores, efectos fijos por provincia de residencia, por cohorte de nacimiento y por año; en el Modelo 3, se agregan los términos de interacciones entre las dummies por provincia y las temporales y se incluye el gasto público consolidado per cápita total.

Fuente: Elaboración propia sobre la base de EPH, INDEC y DAGPyPS, MECON.

Según los modelos teóricos mencionados en la Sección 1, se espera que estos índices de persistencia intergeneracional varíen con los niveles de gastos públicos que experimentaron los hijos cuando eran adolescentes o jóvenes. Como primera exploración empírica de esta hipótesis, se reportan en el Gráfico 1 los CPE estimados a partir del modelo intergeneracional básico (1), que relaciona los años de educación de los hijos con el de sus padres, para tres niveles ${ }^{28}$ de las distintas medidas consideradas de gasto público. En general, se aprecia un aumento significativo en esta medida de inmovilidad intergeneracional cuando el nivel promedio de gasto per cápita experimentado por los hijos en su juventud disminuye de alto a bajo.

En el Cuadro 3 se reportan los resultados de la estimación del modelo intergeneracional del ingreso (2) que incluye, además de las distintas variables de control, el logaritmo del ingreso predicho del padre y del gasto público promedio en la juventud del hijo así como un término de interacción entre esas dos variables que permite examinar el efecto de un mayor nivel de GPCpc en la persistencia intergeneracional del ingreso medida por la EII (el coeficiente del log del ingreso paterno).

28 La clasificación de los niveles de gasto en bajo, medio y alto surge de dividir en terciles la distribución del gasto público consolidado per cápita promedio en la juventud de cada hijo adulto incluido en la muestra principal. 


\section{GRAFICO 1}

\section{CPE ESTIMADO A PARTIR DEL MODELO INTERGENERACIONAL BASICO PARA TRES NIVELES DE GASTO}
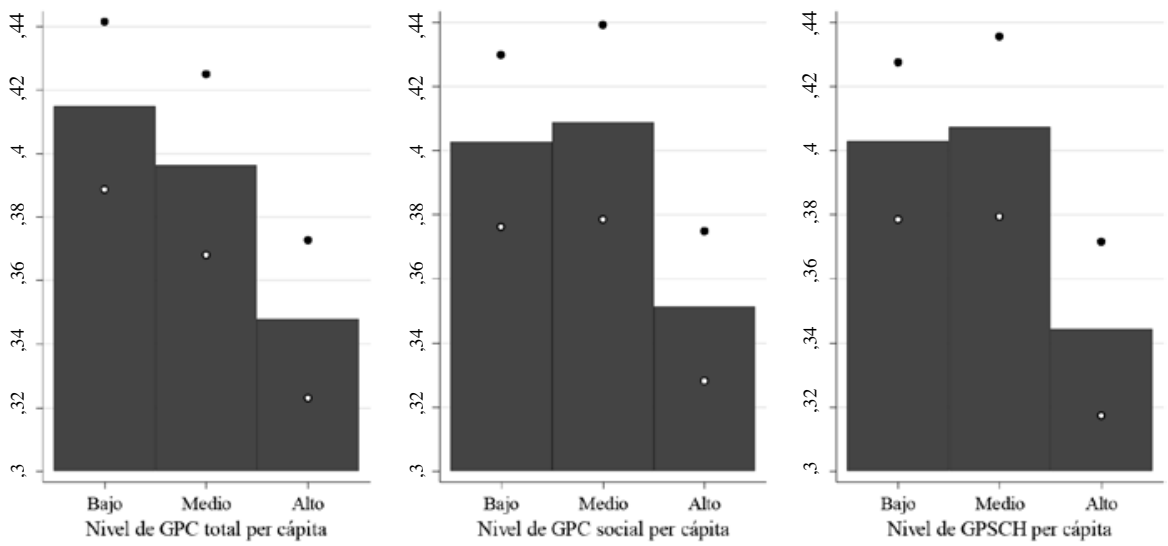

CPE

L.I. int. conf. $95 \%$

- L.S. int. conf. $95 \%$

Nota: El modelo utilizado para estimar el CPE que relaciona la educación de padres e hijos no incluye ninguna variable de control.

Fuente: Elaboración propia sobre la base de EPH, INDEC y DAGPyPS, MECON.

El ingreso estimado del padre tiene un efecto positivo y estadísticamente significativo al $1 \%$ en el ingreso del hijo. Por su parte, la medida de gasto público considerada también presenta un efecto positivo en el ingreso de los hijos, que es estadísticamente significativo, en particular cuando se incluyen en el modelo términos de interacción entre los efectos fijos locales y temporales y controles por ciertas características provinciales, como por ejemplo la tasa de pobreza por NBI, la tasa de desocupación, la desigualdad (medida con el coeficiente de Gini), la tasa de mortalidad infantil, que están correlacionadas positivamente con algunas categorías del gasto público pero negativamente con el ingreso de los hijos. Según Harknett et al. (2003), la evidencia empírica disponible de la relación entre gasto y resultados de los hijos es mixta. Es decir, a partir de los estudios disponibles no se concluye claramente si el gasto público tiene un efecto positivo en los resultados de los hijos. Además, las inversiones privadas realizadas por los padres no solo en dinero sino también en tiempo y otros factores ambientales afectan el bienestar de los hijos. Si estos factores varían entre cohortes podrían disminuir o, incluso, eliminar el efecto directo del gasto público. Asimismo, el término de interacción entre el GPSCH y el ingreso del padre tiene el signo esperado, siendo negativo y estadísticamente significativo al $1 \%$. En principio, 
este resultado indica que a mayores niveles de inversión pública en capital humano experimentados en la juventud, menor es la persistencia intergeneracional de ingresos medida por la EII.

\section{CUADRO 3}

EFECTO DEL GASTO PUBLICO CONSOLIDADO PER CAPITA SOBRE

LA ELASTICIDAD INTERGENERACIONAL DEL INGRESO Y EL COEFICIENTE DE PERSISTENCIA EDUCATIVA INTERGENERACIONAL

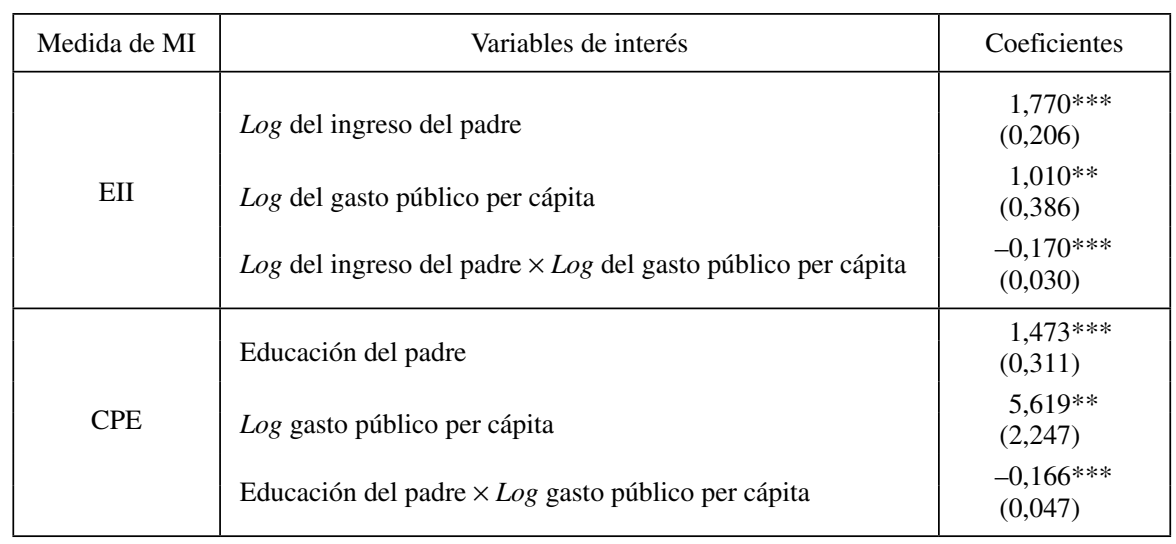

Nota: $* * * p$-value $<0,01, * * p$-value $<0,05, * p$-value $<0,1$. Entre paréntesis se reportan los errores estándares agrupados a nivel provincial. El modelo estimado incluye además de las variables de interés, controles por el sexo y la edad del hijo y de los padres (polinomio cuártico), efectos fijos por provincia de residencia, dummies por año, dummies por cohorte y un conjunto de variables de control por características provinciales promedios existentes durante la juventud de los hijos (los recursos tributarios provinciales, la carga tributaria nacional por provincia, la tasa de desocupación, el nivel de desigualdad, la tasa de crecimiento del PBG, la tasa de pobreza por NBI, la tasa de asistencia a cada nivel educativo, los años de educación promedio de la PET, la cantidad total de población, la proporción de la población sin cobertura de salud, la tasa de mortalidad infantil (por mil nacidos vivos), la tasa de mortalidad total (por mil habitantes), el porcentaje de la población sin acceso a agua corriente y sin acceso a desagües cloacales, el partido político del gobernador de cada provincia en relación con el del presidente al mando), la proporción del gasto público per cápita destinado a otras partidas y términos de interacción entre las dummies locales y temporales.

Fuente: Elaboración propia sobre la base de varias fuentes de información. Ver la sección de datos para más detalles.

Las estimaciones para el modelo intergeneracional educativo, también reportadas en el Cuadro 3, indican que la educación del padre tiene un efecto positivo y estadísticamente significativo a un nivel de significancia del 1\%. El coeficiente del GPSCH presenta también el signo positivo esperado y resulta estadísticamente significativo. El término de interacción entre el GPSCH y la educación del padre, por su parte, tiene el signo 
negativo esperado, siendo además estadísticamente significativo. Según los coeficientes estimados para el modelo más completo, un incremento del $1 \%$ en el GPSCH reduce la elasticidad intergeneracional del ingreso en 0,170 puntos porcentuales (p.p.) y la CPE en 0,166 p.p.

Una forma de evaluar la magnitud de los efectos estimados es comparándolos con los obtenidos por estudios similares que analicen el impacto del gasto público en alguna de estas medidas de inmovilidad intergeneracional. Pero estos estudios son casi inexistentes. No obstante, ML realizan estimaciones relativamente comparables, obteniendo un impacto negativo del gasto público total de Estados Unidos en la EII de 0,128 , considerando un modelo con efectos fijos locales pero sin otros controles adicionales. Las estimaciones aquí obtenidas para el gasto público total, a partir de la especificación más simple similar a la de ML, indican que este efecto sería igual a 0,148 .

Otra forma de interpretar los términos de interacción estimados es evaluando la EII y el CPE en distintos niveles del gasto. En el Cuadro 4 se reportan las EII y los CPE estimados, considerando tres niveles del gasto (bajo, medio y alto) que surgen de dividir en terciles la distribución del logaritmo del gasto y calcular la derivada del $(\log )$ ingreso o la educación del hijo respecto del ingreso o la educación del padre en el valor medio del gasto de cada tercil. Los resultados indican que un incremento del GPSCH de \$ 622 (gasto promedio per cápita en el tercil más bajo) a \$ 958,6 (el gasto promedio per cápita en el tercil más alto), es decir, en $54 \%$, reduce la EII estimada de 0,673 a 0,600 , esto es, en $12 \%$, y el CPE de 0,405 a 0,334 , el $21 \%$. Estos resultados sugieren que los efectos del GPCpc en ambas medidas de persistencia intergeneracional son modestos, porque se requiere un elevado incremento del gasto para conseguir una reducción económicamente significativa en los niveles de inmovilidad entre generaciones.

Se debe señalar que los resultados se mantienen al considerar diferentes especificaciones del modelo (2) y distintas medidas del GPC como el gasto total, el GPSCpc y el destinado al capital humano de los niños y jóvenes (GPSCH) ${ }^{29}$. Además, la magnitud de los términos de interacción que capturan el efecto del GPCpc en la EII y en el CPE varía con la medida de inversión pública en capital humano de adolescentes y jóvenes que se utilice. En general, los efectos más elevados se obtienen al considerar las categorías de gasto más directamente relacionadas con la inversión pública en el capital humano de los jóvenes.

29 Estas medidas se diferencian entre sí por las categorías de GPSCpc incluidas en cada una. Así, la primera medida es la más amplia e incluye el GPSCpc en salud, promoción y asistencia social, educación total, agua y alcantarillado y vivienda, la segunda surge de restar a la anterior el gasto público en vivienda que se podría considerar un categoría de gasto que no beneficia directamente a niños y jóvenes, la tercera medida que incluye el GPSCpc en salud, promoción y asistencia social y educación total es la utilizada en las estimaciones que se reportan en el texto. Finalmente, la última medida considerada (GPSCH4) surge de agregar categorías de gasto social más específicas y dirigidas a incrementar el capital humano de niños y jóvenes: salud, nutrición y educación. Las estimaciones obtenidas con estas medidas alternativas, así como a partir de distintas especificaciones del modelo de interacción (2), están a disposición del lector que los requiera. 


\section{CUADRO 4}

EII Y CPE ESTIMADOS A PARTIR DEL MODELO DE INTERACCION PARA TRES NIVELES DE GASTO

\begin{tabular}{|c|c|c|c|c|c|c|c|c|c|}
\hline \multirow{2}{*}{$\begin{array}{c}\text { Medida } \\
\text { de MI }\end{array}$} & \multicolumn{3}{|c|}{ Nivel de gasto } & \multicolumn{3}{c|}{ Diferencias en las medidas estimadas según nivel de gasto } \\
\cline { 5 - 10 } & Bajo & Medio & \multirow{2}{*}{ Alto } & \multicolumn{2}{c|}{ Bajo-medio } & \multicolumn{2}{c|}{ Medio-alto } & \multicolumn{2}{c|}{ Bajo-alto } \\
\cline { 5 - 10 } & & & & En nivel & En \% & En nivel & En \% & En nivel & En \% \\
\hline EII & 0,673 & 0,656 & 0,600 & 0,018 & 2,7 & 0,056 & 8,5 & 0,074 & 12,3 \\
\hline CPE & 0,405 & 0,388 & 0,334 & 0,017 & 4,3 & 0,054 & 13,9 & 0,071 & 21,3 \\
\hline
\end{tabular}

Fuente: Elaboración propia sobre la base de estimaciones reportadas en el Cuadro 3.

En resumen, las estimaciones previas aportan evidencia a favor de la hipótesis de que la persistencia intergeneracional del ingreso y de la educación, medida a partir de la EII y el CPE, disminuyen con los incrementos del gasto público. Resulta importante recordar que el modelo a partir de los que se derivan estas conclusiones, incluye además de efectos fijos por provincia, por cohorte de nacimiento, dummies por año, controles por el sexo y la edad del hijo, la educación y edad del padre, un conjunto de controles por características provinciales como la tasa del crecimiento del PBG per cápita, los recursos tributarios recaudados por cada jurisdicción, la carga tributaria nacional por provincia, la tasa de pobreza por NBI, la desigualdad, la tasa de desocupación, la cantidad de población total, los años de escolaridad promedio de la PET, la tasa de matriculación en cada nivel educativo, la tasa de mortalidad total e infantil, entre otros. Además el modelo incorpora la proporción del gasto total que se destina a todas las demás partidas, con el fin de controlar por la correlación que existe entre ellas y aislar el efecto de la medida de GPSCH considerada. También se incluyen interacciones entre las dummies provinciales y de año que permiten capturar tendencias específicas por provincia en el ingreso de los hijos.

La estrategia de identificación subyacente en las estimaciones previas explota la variabilidad temporal del gasto público en cada provincia y no su variabilidad de corte transversal. Es decir, se asume que la incorporación de controles fijos por provincia elimina todos los factores locales constantes en el tiempo, correlacionados con la movilidad intergeneracional y el GPSCH como, por ejemplo, el clima social o político que podrían estar relacionadas tanto con el gasto público como con el ingreso de los hijos adultos. Además, se incluyen controles por características provinciales que varían por cohorte y pueden estar correlacionadas con el gasto público y con el ingreso paterno o de los hijos, como por ejemplo la recaudación tributaria (medida por medio de los recursos tributarios provinciales y la carga tributaria nacional por provincia vigentes para cada cohorte durante su adolescencia 
y juventud $)^{30}$. Si no se incluyeran estos controles por provincia, cualquier diferencia en las EII o en el CPE por niveles de gasto podría ser parcialmente endógena, entre otras razones, porque, dada la misma tasa de impuestos, los cambios en los ingresos de los residentes en una provincia se traduce en cambios en los ingresos públicos. También se incluyen controles por otras características provinciales que varían, no solo localmente, sino también por cohorte, como por ejemplo la tasa de pobreza por NBI, el nivel de desigualdad o la tasa de desocupación promedio existente en la provincia de residencia de cada hijo adulto cuando era adolescente o joven. Estos controles resultan relevantes porque algunas categorías de gasto público, particularmente del gasto público social, se ajustan a las necesidades existentes, de manera que las provincias con más familias pobres tenderán a gastar más que las provincias con menos familias pobres. No obstante, aun cuando se incorporen efectos fijos por provincia y por año, interacciones entre estas dos variables, así como controles por distintas características de los hijos y padres y controles por características provinciales, las estimaciones del efecto del gasto público en la movilidad intergeneracional podrían estar sesgadas si persisten factores inobservables omitidos correlacionados con ambas variables. Por esto, con el fin de analizar la robustez de estos resultados en la siguiente sección se presentan las estimaciones obtenidas con la técnica de diferencias en diferencias que permite, bajo determinados supuestos, eliminar los problemas de sesgo persistentes.

\subsection{Brechas de movilidad y gasto público: resultados del método de diferencias en diferencias}

En correspondencia con lo afirmado en la Sección 2, la técnica de diferencias en diferencias puede eliminar los problemas de sesgo persistentes en las estimaciones previas si el efecto de los factores inobservables correlacionados con las variables de interés es el mismo entre los hijos que experimentaron distintos niveles de gasto público per cápita en su provincia de residencia. Además este método permite también testear la hipótesis de la existencia de diferencias en las brechas de movilidad entre hijos de padres con alto y bajo nivel educativo asociadas con el nivel de gasto público per cápita ${ }^{31}$. Cuando se consideran las brechas en el CPE por nivel de gasto público, con el fin de disminuir los problemas de multicolinealidad entre el término de interacción de interés y los años de educación del padre se utiliza como medida del entorno socioeconómico familiar el nivel educativo de la madre en lugar de la educación del padre ${ }^{32}$. Con este objetivo se estima el modelo (3) para tres grupos de hijos identificados según el nivel promedio de gasto público per cápita que experimentaron

30 Esta es una diferencia importante con la estrategia de identificación utilizada por Mayer y Lopoo (2008) que no incluyen en sus modelos estimados ningún control por factores locales que varían en el tiempo o por cohorte y que pueden estar correlacionados con las variables de interés, sesgando las estimaciones. El nivel educativo utilizado como umbral es el secundario completo, entonces se considera que los padres con un nivel educativo mayor al secundario completo tienen un nivel educativo alto, ocurriendo lo contrario con aquellos padres con secundario completo o un nivel educativo menor.

32 No obstante, la consideración del nivel educativo del padre como umbral para el cómputo de las brechas de movilidad no modifica sustancialmente las conclusiones obtenidas. 
durante su juventud en sus provincias de residencia: bajo, medio y alto. En el Cuadro 5 se reportan estas estimaciones.

En general, se observan diferencias positivas en los CPE computados entre los hijos de madres con un nivel educativo superior al secundario completo y aquellos con madres que tienen una educación igual o inferior al secundario para los que experimentaron niveles bajos o medios de gasto público (ver Cuadro A2 del Anexo) ${ }^{33}$. Además, esas diferencias resultan significativamente mayores para aquellos que residían, durante su adolescencia, en provincias con niveles de gasto público per cápita bajo en comparación con los que experimentaron niveles altos de GPSCH. La medida considerada de inversión pública en el capital humano de los jóvenes parece tener un impacto significativo en las brechas de movilidad intergeneracional. Así, por ejemplo, de acuerdo con los resultados obtenidos (reportados en el Cuadro A2), entre los hijos que experimentaron durante su adolescencia niveles de GPSCpc en salud, promoción social y educación relativamente bajos (GPSCH), el CPE es mayor en 0,220 para quienes tienen una madre con un nivel educativo bajo en comparación con los hijos de madres con una educación mayor al secundario completo. En tanto entre aquellos que durante su juventud habitaban en provincias con altos niveles de gasto público en salud, promoción social y educación, la brecha de movilidad intergeneracional asociada con el nivel educativo de la madre asciende a 0,150 . Por tanto, la diferencia en los CPE por nivel educativo materno entre los hijos que experimentaron niveles de GPSCH bajo supera en 0,070 a la que se observa entre aquellos que experimentaron niveles altos de este gasto.

\section{CUADRO 5}

DIFERENCIAS EN DIFERENCIAS DE LA EII POR NIVEL EDUCATIVO DEL PADRE Y DEL CPE POR NIVEL EDUCATIVO DE LA MADRE SEGUN NIVEL DE GASTO PUBLICO

\begin{tabular}{|c|c|c|c|}
\hline \multirow{2}{*}{ Medidas de MI } & \multicolumn{3}{|c|}{ Diferencias en diferencias } \\
\cline { 2 - 4 } & $\begin{array}{c}\text { Nivel de gasto } \\
\text { bajo-medio }\end{array}$ & $\begin{array}{c}\text { Nivel de gasto } \\
\text { medio-alto }\end{array}$ & $\begin{array}{c}\text { Nivel de gasto } \\
\text { bajo-alto }\end{array}$ \\
\hline \multirow{2}{*}{ EII } & $-0,053$ & $0,784^{* * *}$ & $0,731^{* * *}$ \\
& $(0,733)$ & $(0,000)$ & $(0,000)$ \\
\hline \multirow{2}{*}{ CPE } & 0,027 & 0,043 & $0,070^{* *}$ \\
& $(0,353)$ & $(0,189)$ & $(0,015)$ \\
\hline
\end{tabular}

Nota: $\quad * * * p$-value $<0,01, * * p$-value $<0,05, *$-value $<0,1$. Entre paréntesis se reportan los $p$-values corregidos por la correlación intraprovincial entre las observaciones. Ver en la nota del Cuadro 3 la descripción de las variables incluidas en el modelo estimado.

Fuente: Elaboración propia sobre la base de varias fuentes de información. Ver la sección de datos para más detalles.

33 Estas diferencias surgen del coeficiente $\delta_{2}$ en el modelo (3) que acompaña el término de interacción entre el logaritmo del ingreso predicho del padre y la dummy que indica si el nivel educativo del padre es bajo (igual o menor a secundario completo). 
Cuando se considera como medida de persistencia socioeconómica intergeneracional la EII, solo se obtienen efectos significativos del gasto público en las brechas de movilidad al comparar los hijos con niveles de gasto en el primer decil y aquellos en el quinto o en el último decil de la distribución del gasto público consolidado (Cuadro 5). Este resultado indica que se requiere un mayor incremento en el gasto público para reducir las brechas de movilidad intergeneracional por estrato socioeconómico cuando se utiliza como medida de bienestar o resultado económico de los hijos su ingreso en lugar de su educación.

\subsection{Las distintas categorías del gasto público y sus efectos en la movilidad intergeneracional}

Los resultados anteriores sugieren que el GPCpc, en particular el agregado de las categorías del gasto público social que parecen más estrechamente relacionadas con la inversión pública en capital humano de niños y adolescentes, tienen un efecto significativo y positivo en la movilidad intergeneracional así como en las brechas de movilidad. No obstante, desde el punto de vista de la política pública, es relevante determinar también si algunas categorías particulares del gasto público social resultan más efectivas que otras para reducir los niveles de persistencia socioeconómica intergeneracional. La elevada correlación existente entre las distintas categorías de gasto dificulta la identificación del efecto individual de cada una. Por eso en todos los modelos estimados se incluye como variable de control la proporción del gasto destinada al conjunto de partidas no consideradas y su interacción con el ingreso y los años de educación del padre según corresponda.

Los resultados de la estimación de la ecuación (2) para la MII se reportan en el Cuadro 6. Nuevamente, en todos los casos el ingreso estimado del padre tiene un efecto positivo y estadísticamente significativo al $1 \%$ en el ingreso del hijo y la mayoría de las categorías de gasto público consideradas presentan un efecto positivo en el ingreso de los hijos. Sin embargo, este efecto positivo del gasto público no es significativo en el caso de la educación básica. Esta falta de significancia estadística se podría deber en parte al hecho de que esta partida del gasto no beneficia directamente a la mayoría de los jóvenes de 18 a 24 años $^{34}$, sino a los niños y adolescentes.

Los términos de interacción entre el GPCpc y el ingreso del padre tienen el signo esperado, siendo negativos para casi todas las categorías de gasto público social y estadísticamente significativos en las tres especificaciones, salvo en el caso del gasto en vivienda y urbanismo. Esto podría estar relacionado con la incidencia distributiva de algunas partidas de este gasto (como las asociadas con planes asignados con contrapartida de cuotas) que no tienen, a diferencia de las restantes, un claro sesgo propobre. En general, este sector es quizás el que presenta mayor variabilidad en los resultados de los estudios de incidencia distributiva (Gasparini et al., 2000). Algunas de estas investigaciones, como la desarrollada por Paqueo y Lee (2000), encuentran una incidencia uniforme y no propobre del gasto en vivienda.

34 A excepción de aquellos que cursen con sobreedad los estudios primarios o secundarios. 


\title{
CUADRO 6
}

\begin{abstract}
EFECTO DE LAS CATEGORIAS DEL GASTO PUBLICO SOCIAL CONSOLIDADO PER CAPITA SOBRE LA ELASTICIDAD INTERGENERACIONAL DEL INGRESO Y EL COEFICIENTE DE PERSISTENCIA EDUCATIVA
\end{abstract}

\begin{tabular}{|c|c|c|c|c|}
\hline \multirow{2}{*}{ Categorías GPC } & \multicolumn{2}{|c|}{ Modelo intergeneracional del ingreso } & \multicolumn{2}{|c|}{ Modelo intergeneracional educativo } \\
\hline & Variables de interés & Coeficientes & Variables de interés & Coeficientes \\
\hline Salud & $\begin{array}{l}\text { Log del ingreso del padre } \\
\text { Log gasto público per cápita } \\
\text { Log del ingreso del padre } \mathrm{x} \\
\text { Log gasto público per cápita }\end{array}$ & $\begin{array}{c}1,513^{* * *} \\
(0,191) \\
1,267 * * * \\
(0,330) \\
-0,155^{* * *} \\
(0,045)\end{array}$ & $\begin{array}{l}\text { Educación del padre } \\
\text { Log gasto público per cápita } \\
\text { Educación del padre x } \\
\text { Log gasto público per cápita }\end{array}$ & $\begin{array}{l}1,136 * * * \\
(0,167) \\
5,403 * * * \\
(1,883) \\
-0,120 * * * \\
(0,032)\end{array}$ \\
\hline Atención médica & $\begin{array}{l}\text { Log del ingreso del padre } \\
\text { Log gasto público per cápita } \\
\text { Log del ingreso del padre } \mathrm{x} \\
\text { Log gasto público per cápita }\end{array}$ & $\begin{array}{c}1,308^{* * *} \\
(0,181) \\
0,817 * * * \\
(0,273) \\
-0,154 * * \\
(0,056)\end{array}$ & $\begin{array}{l}\text { Educación del padre } \\
\text { Log gasto público per cápita } \\
\text { Educación del padre x } \\
\text { Log gasto público per cápita }\end{array}$ & $\begin{array}{c}0,808^{* * *} \\
(0,159) \\
1,662 \\
(1,764) \\
-0,077^{*} \\
(0,044)\end{array}$ \\
\hline Obras sociales & $\begin{array}{l}\text { Log del ingreso del padre } \\
\text { Log gasto público per cápita } \\
\text { Log del ingreso del padre } \mathrm{x} \\
\text { Log gasto público per cápita }\end{array}$ & $\begin{array}{l}1,385^{* * *} \\
(0,133) \\
1,672^{* * *} \\
(0,377) \\
-0,170^{* * *} \\
(0,039)\end{array}$ & $\begin{array}{l}\text { Educación del padre } \\
\text { Log gasto público per cápita } \\
\text { Educación del padre x } \\
\text { Log gasto público per cápita }\end{array}$ & $\begin{array}{c}1,096^{* * *} \\
(0,167) \\
4,921 * * \\
(1,991) \\
-0,130 * * * \\
(0,035)\end{array}$ \\
\hline $\begin{array}{l}\text { Promoción y asistencia } \\
\text { social }\end{array}$ & $\begin{array}{l}\text { Log del ingreso del padre } \\
\text { Log gasto público per cápita } \\
\text { Log del ingreso del padre } \mathrm{x} \\
\text { Log gasto público per cápita }\end{array}$ & $\begin{array}{c}1,281 * * * \\
(0,144) \\
0,819 * * \\
(0,316) \\
-0,187 * * * \\
(0,035)\end{array}$ & $\begin{array}{l}\text { Educación del padre } \\
\text { Log gasto público per cápita } \\
\text { Educación del padre x } \\
\text { Log gasto público per cápita }\end{array}$ & $\begin{array}{c}0,988^{* * *} \\
(0,181) \\
3,951 * * \\
(1,495) \\
-0,171 * * * \\
(0,054)\end{array}$ \\
\hline $\begin{array}{l}\text { Promoción y asistencia } \\
\text { social pública }\end{array}$ & $\begin{array}{l}\text { Log del ingreso del padre } \\
\text { Log gasto público per cápita } \\
\text { Log del ingreso del padre } \mathrm{x} \\
\text { Log gasto público per cápita }\end{array}$ & $\begin{array}{l}1,189^{* * *} \\
(0,103) \\
1,175^{* * *} \\
(0,187) \\
-0,188^{* * *} \\
(0,032)\end{array}$ & $\begin{array}{l}\text { Educación del padre } \\
\text { Log gasto público per cápita } \\
\text { Educación del padre x } \\
\text { Log gasto público per cápita }\end{array}$ & $\begin{array}{c}0,886 * * * \\
(0,134) \\
3,872 * * * \\
(0,953) \\
-0,187 * * * \\
(0,050)\end{array}$ \\
\hline Educación y cultura & $\begin{array}{l}\text { Log del ingreso del padre } \\
\text { Log gasto público per cápita } \\
\text { Log del ingreso del padre } \mathrm{x} \\
\text { Log gasto público per cápita }\end{array}$ & $\begin{array}{c}1,426 * * * \\
(0,259) \\
0,659^{*} \\
(0,374) \\
-0,173^{* * *} \\
(0,040)\end{array}$ & $\begin{array}{l}\text { Educación del padre } \\
\text { Log gasto público per cápita } \\
\text { Educación del padre x } \\
\text { Log gasto público per cápita }\end{array}$ & $\begin{array}{c}1,062 * * * \\
(0,277) \\
4,522 * \\
(2,468) \\
-0,153 * * * \\
(0,049)\end{array}$ \\
\hline
\end{tabular}


Cuadro 6 (continuación)

\begin{tabular}{|c|c|c|c|c|}
\hline \multirow{2}{*}{ Categorías GPC } & \multicolumn{2}{|c|}{ Modelo intergeneracional del ingreso } & \multicolumn{2}{|c|}{ Modelo intergeneracional educativo } \\
\hline & Variables de interés & Coeficientes & Variables de interés & Coeficientes \\
\hline Educación básica & $\begin{array}{l}\text { Log del ingreso del padre } \\
\text { Log gasto público per cápita } \\
\text { Log del ingreso del padre } \mathrm{x} \\
\text { Log gasto público per cápita }\end{array}$ & $\begin{array}{c}1,318 \text { *** } \\
(0,277) \\
0,363 \\
(0,405) \\
-0,169 * * * \\
(0,051)\end{array}$ & $\begin{array}{l}\text { Educación del padre } \\
\text { Log gasto público per cápita } \\
\text { Educación del padre x } \\
\text { Log gasto público per cápita }\end{array}$ & $\begin{array}{c}0,855^{* * *} \\
(0,190) \\
2,644 \\
(2,629) \\
-0,135^{* * *} \\
(0,042)\end{array}$ \\
\hline $\begin{array}{l}\text { Educación superior y } \\
\text { universitaria }\end{array}$ & $\begin{array}{l}\text { Log del ingreso del padre } \\
\text { Log gasto público per cápita } \\
\text { Log del ingreso del padre } \mathrm{x} \\
\text { Log gasto público per cápita }\end{array}$ & $\begin{array}{l}1,282^{* * *} \\
(0,114) \\
1,397 * * * \\
(0,269) \\
-0,196^{* * *} \\
(0,041)\end{array}$ & $\begin{array}{l}\text { Educación del padre } \\
\text { Log gasto público per cápita } \\
\text { Educación del padre x Log } \\
\text { gasto público per cápita }\end{array}$ & $\begin{array}{c}1,006^{* * *} \\
(0,132) \\
3,475^{* *} \\
(1,398) \\
-0,177^{* * *} \\
(0,041)\end{array}$ \\
\hline Vivienda y urbanismo & $\begin{array}{l}\text { Log del ingreso del padre } \\
\text { Log gasto público per cápita } \\
\text { Log del ingreso del padre } \mathrm{x} \\
\text { Log gasto público per cápita }\end{array}$ & $\begin{array}{c}0,666^{* * *} \\
(0,077) \\
-0,357 * * \\
(0,165) \\
-0,015 \\
(0,036)\end{array}$ & $\begin{array}{l}\text { Educación del padre } \\
\text { Log gasto público per cápita } \\
\text { Educación del padre x Log } \\
\text { gasto público per cápita }\end{array}$ & $\begin{array}{c}0,584 * * * \\
(0,128) \\
-1,418 * * \\
(0,532) \\
-0,086 \\
(0,056)\end{array}$ \\
\hline Agua y alcantarillado & $\begin{array}{l}\text { Log del ingreso del padre } \\
\text { Log gasto público per cápita } \\
\text { Log del ingreso del padre } \mathrm{x} \\
\text { Log gasto público per cápita }\end{array}$ & $\begin{array}{l}0,740^{* * *} \\
(0,051) \\
0,381^{* *} \\
(0,161) \\
-0,062^{* *} \\
(0,029)\end{array}$ & $\begin{array}{l}\text { Educación del padre } \\
\text { Log gasto público per cápita } \\
\text { Educación del padre x Log } \\
\text { gasto público per cápita }\end{array}$ & $\begin{array}{l}0,425^{* * *} \\
(0,063) \\
0,635 \\
(0,499) \\
-0,040 \\
(0,038)\end{array}$ \\
\hline
\end{tabular}

Nota: $\quad * * * p$-value $<0,01, * * p$-value $<0,05, * p$-value $<0,1$. Entre paréntesis se reportan los errores estándares agrupados a nivel provincial. Ver en la nota del Cuadro 3 la descripción de las variables explicativas incluidas en el modelo estimado.

Fuente: Elaboración propia sobre la base de varias fuentes de información. Ver la sección de datos para más detalles.

Asimismo, cuando se considera el GPCpc en agua y alcantarillado, el término de interacción negativos entre esta categoría de gasto y el ingreso paterno predicho también resulta estadísticamente significativo. En principio, estos resultados indican que a mayores niveles de gasto público (en las principales categorías del gasto público social) experimentados en la juventud, menor es la persistencia intergeneracional de ingresos medida por la EII.

Las estimaciones correspondientes al modelo intergeneracional educativo se muestran en la última columna del Cuadro 6. Se observa que la educación del padre tiene en todos los casos un efecto positivo y estadísticamente significativo (a un nivel de significancia del 1\%) en los años de educación obtenido por sus hijos. Los coeficientes del GPCpc presentan también signos positivos en la mayoría de las categorías consideradas. Los términos de interacción entre el GPCpc y la educación del padre, por su parte, tienen en todas las categorías el signo negativo esperado, siendo además estadísticamente 
significativos en el caso del GPCpc en salud (su subcategoría, obras sociales), en promoción y asistencia social, en educación total, media y superior.

Asimismo, la magnitud del efecto de las categorías del GPSCpc sobre la EII y el CPE varía según la partida de gasto social considerada. El gasto en promoción y asistencia social así como el gasto en educación superior son las dos categorías de GPSCpc con el mayor impacto en la EII y en el CPE. El efecto comparativamente más alto del gasto en educación superior en ambas medidas de persistencia intergeneracional probablemente esté relacionado con el tramo de edad de los hijos en la que se mide la inversión pública en capital humano: 18 a 24 años, siendo este grupo etario el principal beneficiario directo de esta partida del gasto educativo. En resumen, los resultados del Cuadro 6 sugieren que determinadas categorías del gasto público, especialmente las que tienen un impacto directo en el capital humano, son más efectivas que otras para aumentar la movilidad intergeneracional.

Resulta de interés también examinar si alguna de las categorías del gasto público que no se destina a servicios sociales tiene un efecto significativo de las medidas de persistencia intergeneracional analizadas. En particular, el gasto público en seguridad y defensa podría tener un impacto en la movilidad entre generaciones que puede ser positivo o negativo dependiendo de cómo esta categoría de gasto afecta otras variables, como por ejemplo la desigualdad y el crecimiento que tienen, a su vez, un impacto en la MI. Existen distintos argumentos que explican las relaciones potenciales entre gasto militar y bienestar económico. Algunos fundamentan la existencia de una relación positiva entre este tipo de gasto y el crecimiento económico así como una negativa entre aquel y la desigualdad en la distribución del ingreso, señalando que un incremento en el gasto militar aumenta la demanda agregada y el empleo en la economía (Benoit, 1978). Como esta expansión en la economía beneficia relativamente más a los pobres mejora la distribución del ingreso. Knight, Loayzan y Villanueva (1996) en su estudio para 44 países ofrece amplia evidencia de que el gasto en defensa tiene un impacto positivo en el crecimiento. No obstante, otra corriente de argumentos postula la ausencia de cualquier relación causal entre gasto militar y crecimiento económico (Biswas y Ram, 1986; Payne y Ross, 1992; Kim, 1996; Dakurah, Davis, y Sampath, 2001). En cambio, según otros autores un mayor gasto en defensa disminuye los fondos destinados a partidas sociales como educación, salud y promoción social, retardando el crecimiento económico al reducir la inversión en capital humano. Este argumento, denominado del crowding-out del gasto militar (o guns-and-butter argument), fue articulado originalmente por Russett (1969) sobre la base de evidencia empírica para Estados Unidos, Francia y el Reino Unido. No obstante, en un estudio seminal Yildirim y Sezgin (2002) mostraron que existe un trade-off negativo entre defensa y salud pero uno positivo entre defensa y educación en Turquía. Según Ali (2011), los resultados de Russett (1969) podrían reflejar la dinámica subyacente de las economías desarrolladas, mientras que los hallazgos de Yildirim y Sezgin (2002) representan mejor la situación de un país en desarrollo con un conjunto de instituciones diferentes. En definitiva, no existen resultados concluyentes en la literatura respecto de las relaciones entre gasto en defensa y bienestar. Por tanto, es difícil adelantar alguna hipótesis acerca del efecto potencial del gasto en defensa o seguridad interior en la movilidad intergeneracional. 
En el Cuadro 7 se presentan las estimaciones del modelo de interacción para el gasto en seguridad y defensa total, así como para el gasto en seguridad interior. Los resultados obtenidos sugieren que ambas partidas del gasto público tienen un efecto positivo y significativo tanto en el ingreso como en la educación de los hijos. Además, el signo negativo y estadísticamente significativo del término de interacción bajo análisis sugiere que un incremento en el gasto en defensa o en seguridad reduce las medidas de persistencia intergeneracional consideradas (la EII y el CPE). No obstante, los resultados deberían ser interpretados con precaución debido a la elevada correlación positiva existente entre el gasto en seguridad y el gasto en servicios sociales $(r=0,95)$ que dificultan aislar el efecto individual de cada tipo de gasto.

\section{CUADRO 7}

EFECTO DEL GASTO PUBLICO CONSOLIDADO EN DEFENSA Y SEGURIDAD SOBRE LAS MEDIDAS DE PERSISTENCIA INTERGENERACIONAL

\begin{tabular}{|c|c|c|}
\hline Medidas GPCpc & Variables de interés & Coeficientes \\
\hline \multicolumn{3}{|c|}{ Efectos en el coeficiente de persistencia educativa } \\
\hline Seguridad y defensa & $\begin{array}{l}\text { Educación del padre } \\
\text { Log gasto público per cápita } \\
\text { Educación del padre } \times \text { Log gasto público per cápita }\end{array}$ & $\begin{array}{l}1,282 * * * \\
(0,242) \\
4,730 * * \\
(1,946) \\
-0,179 * * * \\
(0,048)\end{array}$ \\
\hline Seguridad interior & $\begin{array}{l}\text { Educación del padre } \\
\text { Log gasto público per cápita } \\
\text { Educación del padre } \times \text { Log gasto público per cápita }\end{array}$ & $\begin{array}{l}0,905 * * * \\
(0,131) \\
5,714 * * \\
(2,044) \\
-0,117 * * * \\
(0,029)\end{array}$ \\
\hline \multicolumn{3}{|c|}{ Efectos en la elasticidad intergeneracional del ingreso } \\
\hline Seguridad y defensa & $\begin{array}{l}\text { Log del ingreso del padre } \\
\text { Log del gasto público per cápita } \\
\text { Log del ingreso del padre } \times \text { Log del gasto público per cápita }\end{array}$ & $\begin{array}{l}1,631 * * * \\
(0,200) \\
1,570 * * * \\
(0,533) \\
-0,195 * * * \\
(0,039)\end{array}$ \\
\hline Seguridad interior & $\begin{array}{l}\text { Log del ingreso del padre } \\
\text { Log del gasto público per cápita } \\
\text { Log del ingreso del padre } \times \text { Log del gasto público per cápita }\end{array}$ & $\begin{array}{l}1,149 * * * \\
(0,109) \\
0,963 * * \\
(0,424) \\
-0,111^{* * *} \\
(0,022)\end{array}$ \\
\hline
\end{tabular}

Nota: $\quad * * * p$-value $<0,01, * *$-value $<0,05, *$ p-value $<0,1$. Entre paréntesis se reportan los errores estándares agrupados a nivel provincial. Ver en la nota del Cuadro 3 la descripción de las variables incluidas en el modelo estimado.

Fuente: Elaboración propia sobre la base de varias fuentes de información. Ver la sección de datos para más detalles. 


\subsection{Gasto público y movilidad intergeneracional entre estratos de ingresos}

Los resultados analizados en las secciones previas sugieren que el gasto público redujo los niveles promedio de persistencia socioeconómica intergeneracional. Pero no permiten saber si esto se debe a un incremento en la movilidad ascendente o en la movilidad descendente de los hijos con relación a la situación original de sus padres. Con el fin de examinar este punto se considera como medida de movilidad ascendente ${ }^{35}$ la probabilidad de que el percentil del hijo en la distribución de ingresos de su cohorte supere el percentil en el que puede clasificarse a su padre en función de su ingreso predicho ${ }^{36}$. Formalmente, sea $Y_{h i}$ y $Y_{p i}$ el ingreso del i-ésimo hijo y padre con funciones de distribución acumulada marginales $F_{h i}$ y $F_{p i}$, respectivamente, la movilidad ascendente se define como:

$$
v_{i}=\operatorname{Prob}\left[F_{h i}-F_{p i}>\tau\right]
$$

Esta medida de movilidad, a diferencia de las probabilidades de transición normalmente consideradas, tiene la ventaja de permitir considerar movimientos pequeños de los hijos en su posición relativa a la de sus padres, que son ignorados por las probabilidades de transición. En efecto, el valor de $\tau$ controla la magnitud de los movimientos en la posición relativa, de manera que a menor $\tau$, se considerarán movimientos más pequeños.

Con el fin de examinar el efecto del gasto público en esta medida de movilidad ascendente se estima el siguiente modelo probit:

$$
\begin{aligned}
\operatorname{Prob}\left[v_{i}=1\right] & =\operatorname{Prob}\left[F_{h i}-F_{p i}>\tau \mid x\right] \\
& =\Phi\left[\alpha+\delta_{1} G_{c j}+\gamma A_{i c j}+\theta X_{c j}+\phi D_{j}+\pi D_{t}+\lambda D_{c}+\vartheta\left(D_{t} \times D_{j}\right)+\varepsilon_{i c j t}\right]
\end{aligned}
$$

donde $\Phi[\cdot]$ es la función de distribución normal acumulada estándar, $c$ indexa la cohorte de nacimiento, $j$ la provincia de residencia, y $t$ el año; $G_{c j}$ es el logaritmo del gasto público consolidado per cápita; $A_{i c j}$ son controles individuales que incluyen el sexo del hijo, un polinomio de grado cuarto en su edad, un polinomio cuadrático en la edad del padre; $X_{c j}$ es un vector de variables de control a nivel provincial previamente descriptas en la Sección 2 que varían por cohorte.

35 Esta medida fue introducida por Bhattacharya y Mazumder (2011).

36 Ver Sección 2 para más detalles metodológicos relacionados con esta estimación. Es importante aclarar que para clasificar a los hijos en los percentiles de la distribución del ingreso de su generación también se consideró su ingreso predicho utilizando la misma ecuación de ingreso empleada para predecir el ingreso de los padres. De otra forma, si se utilizara el ingreso observado del hijo pero el predicho del padre, se estarían comparando cuantiles de distribuciones de ingresos distintos, pudiendo sesgar la medida de movilidad ascendente considerada. 
Los resultados de la estimación del modelo probit de la ecuación (5) para $\tau=0$ se muestran en el Cuadro 8.

\section{CUADRO 8}

EFECTOS DEL GASTO PUBLICO SOBRE LA PROBABILIDAD DE MOVILIDAD ASCENDENTE. RESULTADOS DEL MODELO PROBIT

\begin{tabular}{|c|c|c|c|c|c|}
\hline \multicolumn{3}{|c|}{ Coeficiente del modelo probit } & \multicolumn{3}{|c|}{ Efecto marginal } \\
\hline \multicolumn{3}{|c|}{$\begin{array}{l}3,067 * * * \\
(0,995)\end{array}$} & \multicolumn{3}{|c|}{$\begin{array}{l}0,012 * * * \\
(0,378)\end{array}$} \\
\hline \multicolumn{6}{|c|}{ Probabilidad predicha } \\
\hline \multicolumn{2}{|c|}{ Gasto bajo } & \multicolumn{2}{|c|}{ Gasto medio } & \multicolumn{2}{|c|}{ Gasto alto } \\
\hline \multicolumn{2}{|c|}{$\begin{array}{c}0,406 \\
0,252-0,560\end{array}$} & \multicolumn{2}{|c|}{$\begin{array}{c}0,531 \\
0,465-0,597\end{array}$} & \multicolumn{2}{|c|}{$\begin{array}{c}0,856 \\
0,730-0,981\end{array}$} \\
\hline \multicolumn{6}{|c|}{ Diferencias en la probabilidad según nivel de gasto } \\
\hline \multicolumn{2}{|c|}{ Bajo-medio } & \multicolumn{2}{|c|}{ Medio-alto } & \multicolumn{2}{|c|}{ Bajo-alto } \\
\hline En nivel & En \% & En nivel & $E n \%$ & En nivel & En $\%$ \\
\hline$-0,125$ & $-30,9$ & $-0,325$ & $-61,2$ & $-0,450$ & $-52,6$ \\
\hline
\end{tabular}

Nota: $\quad * * * p$-value $<0,01, * *$-value $<0,05, *$-value $<0,1$. Entre paréntesis se reportan los errores estándares agrupados a nivel provincial. Bajo las probabilidades predichas se reportan los intervalos de confianza al $95 \%$ computados con el método delta. Ver en la nota del Cuadro 3 las variables incluidas en el modelo estimado. Los efectos marginales fueron computados en los valores promedios de las variables explicativas.

Fuente: Elaboración propia sobre la base de varias fuentes de información. Ver la sección de datos para más detalles.

En proporción a lo esperado, la medida considerada de gasto público (GPSCH) tiene efecto positivo y significativo en la probabilidad de movilidad de los hijos de ubicarse en un percentil superior al de su padre para la especificación más completa del modelo (5). Según los efectos marginales computados a partir del modelo (5), en los valores promedios de las variables explicativas, un incremento del $1 \%$ en el gasto público social aumenta en 0,012 la probabilidad de movilidad ascendente. Como este incremento del gasto se puede considerar demasiado pequeño, con el fin de tener una idea más clara de la magnitud del efecto del gasto en la probabilidad de los hijos de ubicarse en un percentil superior al de su padre, se estimaron las probabilidades predichas para tres niveles del gasto: bajo, medio y alto (en el valor promedio del gasto público correspondiente a cada tercil de la distribución del gasto).

La especificación más completa del modelo probit estimado indica que un incremento del gasto público per cápita en salud, promoción social y educación de 
\$ 622,4 (valor promedio en el tercil más bajo) a \$ 958,6 (valor promedio en el tercil más alto), esto es, en $54 \%$, aumenta la probabilidad predicha de movilidad ascendente de 0,406 a 0,856 , es decir, en $53 \%$. Según los intervalos de confianza, las diferencias entre estas probabilidades predichas son estadísticamente significativas, al menos a un nivel de significancia del $5 \%$.

Cuando se consideran movimientos ascendentes de mayor magnitud, se observa que el gasto público tiene un efecto significativo para $0<\tau<0,20^{37}$. Es decir, la probabilidad de superar el percentil del padre en magnitudes mayores a cero pero menores a 0,20 son más elevadas para los hijos que experimentaron niveles más altos de gasto público en su juventud. Esto significa que el gasto no solo tiene un efecto positivo en la probabilidad de los hijos de superar el percentil de sus padres sino también en la de abandonar el decil más bajo en el que se encontraban sus padres. En efecto, las estimaciones del modelo probit para $\tau=0,10$ sugieren que el gasto público tiene un efecto positivo en la probabilidad de los hijos de superar el decil en el que se encontraban sus padres. Sin embargo, para valores mayores de $\tau$, concretamente para $\tau=0,20$ no se observan efectos significativos del gasto en la probabilidad de movilidad ascendente. Por tanto, las estimaciones sugieren que el gasto público tiene un impacto limitado en la movilidad intergeneracional ascendente, concretamente parece no tener efectos en la probabilidad de que los hijos superen el quintil en el que se encontraba su padre. No obstante, cuando se consideran movimientos ascendentes de menor magnitud se obtienen efectos positivos y significativos. Este resultado es consistente con los impactos relativamente modestos del gasto público en los niveles promedios de persistencia intergeneracional medidos a partir de la EII. No obstante, las estimaciones presentadas en este apartado deben ser interpretadas con precaución, ya que las limitaciones de los datos utilizados dificultan, en general, el análisis de probabilidades de transición del ingreso.

\subsection{Análisis de robustez}

La extensión de la serie histórica del GPC por ubicación geográfica no permite examinar el efecto del gasto público que experimentaron durante la niñez o adolescencia los adultos de la muestra principal. Sin embargo, varios estudios han reportado mayores tasas de retorno de intervenciones en capital humano en la primera infancia que intervenciones en etapas posteriores del ciclo de vida durante la adolescencia, juventud o adultez (Duncan y Brooks-Gunn, 1997; Duncan et al., 1998, Bernal y Camacho, 2010). Esto sucede, entre otras razones, porque la capacidad de los seres humanos para aprender durante la primera infancia es mucho mayor y su conjunto de habilidades básicas es mucho más maleable que en los años posteriores (Heckman, 2000 y 2008). La evidencia empírica sugiere que la habilidad cognitiva se forma relativamente temprano en el ciclo de vida, está prácticamente determinada en su totalidad entre los 8 y 14 años de edad y se vuelve mucho menos maleable con el paso del tiempo (Carneiro y Heckman, 2003). No obstante, otra evidencia sugiere que el momento de la inversión no es relevante o que es más importante cuando se mide cerca del resultado de interés (Mayer, 2002).

37 Estas estimaciones están a disposición del lector que las requiera. 
Con el fin de examinar el efecto de la edad y el período temporal en la que se mide la inversión pública en el capital humano de los hijos se utilizan en esta sección los datos del gasto público provincial per cápita (GPPpc) por finalidad y función para el período 1993-2012 que provienen de la Dirección de Análisis del Gasto Público y Programas Sociales (DAGPyPS) del MECON. Estos datos permiten obtener una medida del gasto público durante la adolescencia de los hijos adultos de la muestra principal. Igual como se observa en el Cuadro A1, los hijos de 25 a 34 años observados durante 2003-2012, tenían entre 15 y 17 años en el período 1993-2012. Aunque existen datos del gasto público nacional para el mismo período, no están distribuidos geográficamente y no se dispone de la información necesaria para hacer esta distribución de forma similar a como se la realizó para el período 1998-2008, en particular no se cuenta con la apertura programática del gasto nacional por finalidad y función, ni con indicadores provinciales apropiados ${ }^{38}$. No obstante, una elevada proporción del GPC particularmente en las partidas más directamente relacionadas con el capital humano de los hijos es ejecutado por los gobiernos provinciales. Así, en promedio, durante 1998-2008, el 40,4\% del GPC es ejecutado por las provincias. En particular, el 80\% del GPC en educación y cultura y más del $90 \%$ del gasto en educación básica es ejecutado por los gobiernos provinciales. Esto refleja la responsabilidad de las provincias en el financiamiento y provisión de los servicios de educación básica en Argentina como resultado de un proceso de descentralización ocurrido principalmente durante los $90^{39}$. Por otra parte, el $69 \%$ del GPC en atención médica es ejecutado por las provincias. Esto responde en gran medida a la modificación introducida en 1992 por medio de la Ley $\mathrm{N}^{\mathrm{O}} 24.061$ que reglamentó la transferencia a las provincias y la CABA de la administración y financiamiento de 20 hospitales e institutos dependientes del gobierno nacional. Durante la década de 1990 también se descentralizaron otras áreas de la política social: vivienda, programas nutricionales y otros programas asistenciales. Esto se refleja en que el 54\% del GPC en promoción y asistencia social total, el $91 \%$ del

38 Por ejemplo, no hay información disponible de la cantidad de alumnos por nivel educativo y provincia para los años 1993 ni 1995, porque el Ministerio de Educación de la Nación no elaboró información estadística para el período 1989-1993 y para 1995 (Ferreres, 2010). No obstante, este constituye un indicador relevante para distribuir el gasto público nacional en educación básica en función de sus principales beneficiarios. De la misma forma, un indicador que se podría utilizar para distribuir el gasto público nacional en atención de la salud entre sus beneficiarios sería la cantidad de población que no cuenta con cobertura de salud. Sin embargo, no hay bases de datos que permitan computar este indicador a nivel provincial para el período 1993-1996.

39 No obstante, el primer proceso de transferencia de servicios educativos de la nación a las provincias se produjo en 1978. Mediante las leyes $\mathrm{N}^{\circ} 21.809$ y No 21.810 se facultó al gobierno nacional a transferir a las provincias los establecimientos de enseñanza preprimaria y primaria que estaban a cargo de la nación. Tres años más tarde, el proceso se completó con la transferencia de los establecimientos para adultos (Curcio, Cetrángolo y Jiménez, 2009). Luego, en 1992 con la Ley N 24.049 se dispuso la transferencia de la administración y financiamiento de los servicios educativos que aún estaban en poder del gobierno nacional a los gobiernos provinciales y a la Ciudad de Buenos Aires (Cetrángolo y Gatto, 2002). En 1993, mediante la Ley Federal de Educación N ${ }^{\circ} 24.185$ se disponen en varias reformas que apoyan la redefinición de los roles administrativos y responsabilidades de financiamiento del sistema educativo para cada nivel de gobierno. Las provincias fueron designadas como las principales administradoras de la educación pública preuniversitaria y de la formación inicial docente en todo el país (Curcio, Cetrángolo y Jiménez, 2009). 
gasto en nutrición y alimentación, el $82 \%$ del gasto en deporte y recreación y $77 \%$ del gasto en vivienda son ejecutados por las provincias (ver Gráfico A1).

Asimismo, este ejercicio permite analizar también en qué medida el gasto público provincial, sin el gasto nacional ni el municipal, es efectivo para reducir los niveles de persistencia socioeconómica intergeneracional.

En el Cuadro 9 se presentan los resultados de la estimación del modelo (1) para el GPPpc total, social y para el gasto público en salud, promoción social y educación (GPSCH). El ingreso estimado del padre tiene un efecto positivo y estadísticamente significativo al $1 \%$ en el ingreso del hijo. Por su parte, la medida de gasto público considerada presenta un efecto positivo en el ingreso y la educación de los hijos. Sin embargo, el efecto positivo del gasto público en la educación de los hijos es significativo al 10\%. Los términos de interacción entre el GPPpc y el ingreso o la educación del padre tienen el signo esperado, siendo negativos y estadísticamente significativos ${ }^{40}$.

\section{CUADRO 9}

\section{EFECTO DEL GASTO PUBLICO PROVINCIAL PER CAPITA \\ EN LA ELASTICIDAD INTERGENERACIONAL DEL INGRESO \\ Y EL COEFICIENTE DE PERSISTENCIA EDUCATIVA}

\begin{tabular}{|c|c|c|}
\hline Medida de MI & Variables de interés & Coeficiente \\
\hline EII & $\begin{array}{l}\text { Log del ingreso del padre } \\
\text { Log gasto público per cápita } \\
\text { Log del ingreso del padre x Log gasto público per cápita }\end{array}$ & $\begin{array}{l}1,269 * * * \\
(0,171) \\
0,427 * * * \\
(0,143) \\
-0,105 * * * \\
(0,029)\end{array}$ \\
\hline СРE & $\begin{array}{l}\text { Educación del padre } \\
\text { Log gasto público per cápita } \\
\text { Educación del padre x Log gasto público per cápita }\end{array}$ & $\begin{array}{c}0,963 * * * \\
(0,258) \\
1,184 * \\
(0,646) \\
-0,097 * * \\
(0,043)\end{array}$ \\
\hline
\end{tabular}

Nota: $* * * p$-value $<0,01, * * p$-value $<0,05, * p$-value $<0,1$. Entre paréntesis se reportan los errores estándares agrupados a nivel provincial.

Fuente: Elaboración propia sobre la base de varias fuentes de información. Ver la sección de datos para más detalles.

40 El mismo resultado se observa con otras medidas de inversión pública en capital humano como la que surge de sumar el gasto público en salud, promoción social, educación, vivienda y agua (denominada GSPCH1) o la que se obtiene al restar de la medida anterior el gasto en vivienda (denominada GSPCH2). Tanto en el caso de la EII como en el caso del CPE, el efecto del gasto público se incrementa levemente en el caso de las medidas que se consideran más directamente beneficiosas para los niños adolescentes. Así, mientras un incremento del 1\% en el GPSCH1 reduce la EII en 0,077 p.p. y el CPE en 0,081 p.p., un aumento del GPSCH3 en el mismo porcentaje disminuye estas medidas de persistencia intergeneracional en 0,105 p.p. y en 0,097 p.p., respectivamente. No obstante, las diferencias en los efectos de las tres medidas de inversión pública en capital humano no son estadísticamente significativas. 
Por otra parte, el efecto del GPPpc tanto en la EII como en el CPE parecen ser menores que el del GPCpc. Así, un incremento del $1 \%$ en el gasto en salud, promoción social y educación reducen la EII en 0,170 p.p. y el CPE, en 0,166 cuando se considera el GPCpc, pero en 0,105 p.p. y 0,097 p.p., respectivamente, en el caso del GPPpc. Además, ambas diferencias son estadísticamente significativas. Este es un resultado esperable porque el GPCpc es mayor, por definición, que el GPPpc. Sin embargo se debe tener en cuenta también que la edad promedio de los hijos en la que se mide el primero (18 a 24 años) es mayor que la edad en la que se mide el segundo (15 a 17 años). Por tanto, como surge de algunos estudios, las tasas de retorno de las intervenciones en capital humano en la niñez o adolescencia son mayores que las de intervenciones en etapas posteriores del ciclo de vida, el efecto del GPPpc podría ser igual o mayor que el del GPCpc.

Cuando se consideran por separado las distintas categorías del gasto público provincial social per cápita ${ }^{41}$ se observa que los gastos en salud, en promoción y asistencia social y en educación total tienen efectos positivos en el ingreso y la educación de los hijos (ver Cuadro A3). Además todos los términos de interacción de estas tres categorías del gasto tienen el signo negativo esperado y resultan estadísticamente significativos sugiriendo que un incremento del gasto público provincial en estas categorías reduce la persistencia intergeneracional de ingresos así como la educativa. Y, a excepción del gasto público en salud, sus efectos individuales en la EII y en el CPE no son significativamente distintos de los estimados para las mismas categorías del GPC. Esto probablemente responde a la elevada participación de los gobiernos provinciales en la ejecución del GPC en estas partidas (ver Gráfico A1).

Un resultado llamativo es la falta de significancia estadística del efecto del gasto en educación básica tanto en el ingreso y educación de los hijos como en las medidas de persistencia socioeconómica entre padres e hijos. No obstante, según se explicó antes, esto podría nuevamente estar relacionado con la edad en la que se mide la inversión pública en educación. En efecto, la medida de inversión pública considerada es el GPP promedio que experimentaron los hijos adultos cuando tenían entre 15 y 17 años. Sin embargo, el GPP en educación básica comprende, además del gasto en educación media, el gasto en educación elemental y educación primaria que no benefician directamente a los hijos en su adolescencia sino durante su niñez. No obstante, otra explicación factible para la falta de significancia del gasto en educación básica es la existencia de deficiencias en la calidad de los servicios educativos públicos. Asimismo, este resultado podría estar relacionado también con la creciente segregación escolar que se observa en Argentina durante el período 1992-2009, según los resultados obtenidos por Gasparini et al. (2012) y Jaume (2013). En efecto, como advierte Krüger (2012), el hecho de que los jóvenes se concentren en determinados centros según su nivel socioeconómico incide en la desigualdad de logros educativos en el nivel medio argentino. De esta forma, la segregación implica que los estudiantes de origen social desfavorecido se encuentran en desventaja por su menor capital económico y cultural y por asistir a escuelas en las que no se pueden beneficiar del intercambio con pares

41 Para el GPP no se dispone de la misma apertura por finalidad y función que para el GPC, por eso se consideran en este análisis menos categorías del gasto público social. 
de distintos segmentos sociales. Adicionalmente, la integración social en la escuela no solo afecta los resultados educativos inmediatos sino también puede incidir en la cantidad de educación demandada luego del egreso y en la inserción laboral (Brunello y Checchi, 2006; Sendón, 2005).

\section{CONCLUSIONES}

El objetivo de esta investigación fue determinar el efecto que tiene en la movilidad socioeconómica intergeneracional en Argentina, el gasto público realizado por los tres niveles de gobierno (nacional, provincial y municipal) que modificaron las inversiones públicas en el capital humano de los niños y adolescentes durante el período 19982008. Específicamente, se buscó evaluar si el gasto público cumple con uno de los objetivos centrales de la política social que es incrementar la movilidad económica intergeneracional y la igualdad de oportunidades, disminuyendo el impacto del origen socioeconómico en el ingreso obtenido en la adultez. Asimismo, se examinó si la brecha de movilidad observada entre los hijos que provienen de trasfondos familiares socioeconómicamente distintos es menor entre las cohortes que experimentaron mayores niveles de gasto público durante su adolescencia y juventud que en aquellas para las cuales el gasto público fue menor.

Los resultados obtenidos sugieren que el gasto público tiene el efecto esperado, incrementando la movilidad intergeneracional tanto del ingreso como la educativa. Sin embargo, no todas las categorías de gasto son igualmente efectivas para conseguir este resultado. Así, se observa una disminución mayor en la persistencia socioeconómica entre generaciones, medida por la EII y por el CPE cuando se incrementan las medidas del GPC más directamente relacionadas con el capital humano de los niños y adolescentes como las que surgen de agregar el gasto en salud, promoción social y educación.

Si bien las estimaciones anteriores surgen de explotar la variabilidad temporal (entre cohortes de nacimiento) del gasto público, controlando por un amplio conjunto de características individuales, y principalmente locales, de las provincias de residencia de los hijos podrán estar sesgadas por la presencia de factores locales inobservables que varían en el tiempo. Una forma de corregir este problema, bajo determinados supuestos, es mediante la estrategia de diferencias en diferencias, que permite examinar el efecto del gasto público en las brechas de movilidad intergeneracional según nivel educativo de los padres. En general, los resultados obtenidos a partir de esta técnica confirman los anteriores. No obstante, se debe señalar que, desde el punto de vista económico, la magnitud de los efectos estimados del gasto público en la movilidad intergeneracional son en general modestos, sugiriendo que se requieren de elevados incrementos en el gasto para disminuir significativamente las medidas de persistencia intergeneracional consideradas o incrementar las probabilidades de movilidad ascendente de los hijos.

Estos hallazgos se deben interpretar con precaución debido a las limitaciones informativas existentes, en particular el gasto público consolidado por provincia solo está disponible para el período 1998-2008. Por tanto, las estimaciones podrían 
cambiar al considerar los niveles de gasto público para otros períodos o al cambiar la edad en el que se observa el ingreso familiar de los hijos adultos. En particular, de acuerdo con lo señalado previamente, varios estudios han reportado mayores tasas de retorno de intervenciones en capital humano en la primera infancia. Por tanto, es probable que los efectos del gasto aquí estimado se incrementen al medir las inversiones públicas en el capital humano durante la niñez de los hijos adultos. No obstante, el análisis de robustez realizado utilizando el gasto público provincial para el período 1993-2004, que permite medir la inversión pública en capital humano ejecutada por los gobiernos locales durante la adolescencia de los hijos (concretamente cuando tenían de 15 a 17 años), sugiere que las principales conclusiones no se modifican al considerar otra franja etaria en la que se mide la inversión pública en el capital humano de los hijos.

\section{REFERENCIAS}

ALI, H. (2011). "Military Expenditures and Human Development: Guns and Butter Arguments Revisited: A Case Study from Egypt”, Peace Economics, Peace Science and Public Policy 17 (1), pp. 1554-8597.

ATLAS, C.M., T.W. GILLIGAN, R.J. HENDERSHOT y M.A. ZUPAN (1995). "Slicing The Federal Government Net Spending Pie: Who Wins, Loses and Why", American Economic Review 85 (3), pp. 624-629.

BECKER, G.S. y N. TOMES (1979). "An Equilibrium Theory of the Distribution of Income and Intergenerational Mobility", Journal of Political Economy 87 (6), pp. 1153-1189.

BEHRMAN, J.R. y P. TAUBMAN (1990). "The Intergenerational Correlation between Children's Adult Earnings and their Parents' Income: Results from The Michigan Panel Survey of Income Dynamics", Review of Income and Wealth 36 (2), pp. 115-127.

BEHRMAN, J.R, A. GAVIRIA y M. SZEKELEY (2001). "Intergenerational Mobility in Latin America", Economía 2 (1), pp. 1-31.

BENOIT, E. (1978). "Growth and Defense in Developing Countries", Economic Development and Cultural Change 26 (2), pp. 271-280.

BERNAL, R. y A. CAMACHO (2010). "La Importancia de los Programas para la Primera Infancia en Colombia", Documentos CEDE 20, Universidad de los Andes, pp. 1-114.

BHATTACHARYA, D. y B. MAZUMDER (2011). "A Nonparametric Analysis of Black-White Differences in Intergenerational Income Mobility in the United States", Quantitative Economics 2 (3), pp. 335-379.

BISWAS, B. y R. RAM (1986). "Military Expenditures and Economic Growth in Less Developed Countries: An Augmented Model and Further Evidence", Economic Development and Cultural Change 34 (2), pp. 361-372.

BLACK, E.S. y P.J. DEVERAUX (2011). "Recent Developments in Intergenerational Mobility", en O. Ashenfelter y D. Card, Handbook of Labor Economics, North-Holland Press, Amsterdam, pp. 190-202.

BOEX, J. y J. MARTINEZ-VAZQUEZ (2005). "The Determinants of the Incidence of Intergovernmental Grants: A Survey of the International Experience", Andrew Young School of Policy Studies Working paper $\mathrm{N}^{\circ}$ 09. 13 de Noviembre de 2013, <http://papers.ssrn.com/sol3/papers.cfm?abstract_id=902454>.

BRUNELLO, G. y D. CHECCHI (2006). "Does School Tracking Affect Equality of Opportunity? New International Evidence", Institute for the Study of Labor, IZA Discussion Paper No 2348. 20 de Febrero de 2013, <http://economicpolicy.oxfordjournals.org/content/22/52/782.short>.

CARNEIRO, P. y J. HECKMAN (2003). "Human Capital Policy", National Bureau of Economic Research, NBER Working Papers N $^{\circ}$ 9495. 20 de Febrero de 2013, <https://www.nber.org/papers/w9495.pdf>.

CETRANGOLO, O. y F. GATTO (2002). "Descentralización Fiscal en Argentina: Restricciones Impuestas por un Proceso Mal Orientado", Biblioteca digital de la Universidad Nacional de Quilmes. 17 de noviembre de 2013, <http://biblioteca.municipios.unq.edu.ar/modules/mislibros/archivos/ Cetr\%E1ngolo-.PDF $>$. 
CORCORAN, M., R. GORDON, D. LAREN y S. GARY (1992). "The Association between Men's Economic Status and Their Family and Community Origins", Journal of Human Resources 27 (3), pp. 575-601.

COUCH, K.A. y D.R. LILLARD (1998). "Sample Selection Rules and the Intergenerational Correlation of Earnings", Labour Economics 5 (3), pp. 313-329.

CURCIO, J., O. CETRANGOLO y J. JIMENEZ (2009). "Fuentes de Financiamiento Educativo", en J. Jiménez, A. Murdochowicz y A. Astorga, Políticas de Financiamiento de la Educación que Favorecen la Cohesión Social, CIEP-ADETEF.

DAGPyPS (2009). Gasto Público Social dirigido a la Niñez en la Argentina 1995-2007, Dirección de Análisis del Gasto Púbico y Programas Sociales (DAGPyPS) y Fondo de Naciones Unidas para Infancia (UNICEF), Buenos Aires.

DAGPyPS (2011). "Serie de Gasto Público Consolidado. Aspectos Metodológicos", Dirección de Análisis del Gasto Púbico y Programas Sociales (DAGPyPS). 19 de noviembre de 2013. <https:// www.mecon.gov.ar/peconomica/docs/resumen_metod.pdf.>.

DAHAN, M. y A. GAVIRIA (2001). "Sibling correlations and intergenerational mobility in Latin America", Economic Development y Cultural Change 49 (3), pp. 537-554.

DAKURAH, H., S. DAVIES y R. SAMPATH (2001). "Defense Spending and Economic Growth in Developing Countries: A Causality Analysis", Journal of Policy Modeling 23 (6), pp. 651-658.

DENG, Z. y D.J. TREIMAN (1997). "The Impact of the Cultural Revolution on Trends in Educational Attainment in the People's Republic of China", The American Journal of Sociology 103 (2), pp. 391-428.

DUFLO, E. (2001). "Schooling and Labor Market Consequences of School Construction in Indonesia: Evidence from an Unusual Policy Experiment", The American Economic Review 91 (4), pp. 795-813.

DUNCAN, G.J. y J. BROOKS-GUNN (1997). Consequences of Growing up Poor, Russell Sage, New York.

DUNCAN, G., W.J. YEUNG, J. BROOKS-GUNN y J.R. SMITH (1998). "How Much Does Childhood Poverty Affect the Life Chances of Children?", American Sociological Review 63 (3), pp. 406-423.

FERRERES, O.J. (2010). Dos Siglos de Economía Argentina 1810-2010: Historia Argentina en Cifras, Fundación Norte y Sur y El Ateneo, Buenos Aires.

FIEL (2008). La Igualdad de Oportunidades en la Argentina. Movilidad Intergeneracional en los 2000, Temas grupo editorial, Buenos Aires.

FONDO MONETARIO INTERNACIONAL (2001). Manual de Estadísticas de Finanzas Públicas, International Monetary Fund, Washington DC.

GASPARINI, L. (2007). "Monitoring the Socio-Economic Conditions in Argentina 1992-2006", CEDLAS, Facultad de Ciencias Económicas, Universidad Nacional de La Plata. 15 de abril de 2009, <http:// www.depeco.econo.unlp.edu.ar/cedlas/monitoreo/pdfs/argentina.pdf.>.

GASPARINI, L., D. JAUME, M. SERIO y E. VAZQUEZ (2012). "La Segregación Escolar entre Escuelas Públicas y Privadas en Argentina. Reconstruyendo la Evidencia”, Desarrollo Económico-Revista de Ciencias Sociales 51, pp. 189-219.

GASPARINI, L., V. ALAIMO, F. CUENIN, M. RABASSA y G. VULETIN (2000). "El Impacto Distributivo del Gasto Público en Sectores Sociales en la Provincia de Buenos Aires. Un Análisis en Base a la Encuesta de Desarrollo Social", Cuadernos de Economía 50, pp. 8-109.

HAIDER, S. y G. SOLON (2006). "Life-Cycle Variation in the Association between Current and Lifetime Earnings", American Economic Review 96 (4), pp. 1308-1320.

HARKNETT, K., I. GARFINKEL, J. BAINBRIDGE, T. SMEEDING, N. FOLBRE y S. McLANAHAN (2003). "Do Public Expenditures Improve Child Outcomes in the U.S.: A Comparison across Fifty States", Center for Research on Child Wellbeing Working Paper No 02. 5 de mayo de 2013, <http:// papers.ssrn.com/sol3/papers.cfm?abstract_id=1809890>.

HECKMAN, J. (2000). "Policies to Foster Human Capital", Research in Economic 54 (1), pp. 3-56.

HECKMAN, J. (2008). "Schools, Skills and Synapses", Economic Inquiry 46 (3), pp. 289-324.

HERTZ, T. y T. JAYASUNDERA (2007). "School Construction and Intergenerational Educational Mobility in Indonesia", Department of Economics, American University, Working Paper $\mathrm{N}^{\circ} 18.17$ de noviembre de 2013, < http://citeseerx.ist.psu.edu/viewdoc/download?doi=10.1.1.686.4386\&rep=rep1\&type=pdf.>.

HERTZ, T., M. MEURS y S. SELCKUK (2009). "Post-Socialism: Evidence from the Bulgarian Case", World development 37 (3), pp. 739-752. 
ICHINO, A., L. KARABARBOUNIS y E. MORETTI (2011), “The Political Economy of Intergenerational Income Mobility", Economic Inquiry 49 (1), pp. 47-69.

JAUME, D.J. (2013). "Un Estudio sobre el Incremento de la Segregación Escolar en Argentina", Documento de Trabajo No 143, Centro de Estudios Distributivos, Laborales y Sociales (CEDLAS), Universidad Nacional de La Plata. 17 de noviembre de 2013, <http://cedlas.econo.unlp.edu.ar/esp/ documentos-de-trabajo.php?page $=7 .>$

JIMENEZ, M. (2002). "Delimitación del Perímetro de la Consolidación Contable Pública y Métodos de Consolidación: Especial Referencia a las Corporaciones Locales", Revista de Contabilidad 5 (9), pp. 147-167.

JIMENEZ, M. (2011). “Un Análisis Empírico de las No Linealidades en la Movilidad Intergeneracional del Ingreso. El Caso de Argentina", Documento de trabajo del CEDLAS N ${ }^{\circ} 114$, Centro de Estudios Distributivos y Laborales (CEDLAS). 2 de marzo de 2011, <http://cedlas.econo.unlp.edu.ar/esp/ documentos-de-trabajo.php?page $=10$. $>$

JIMENEZ, M. (2016). "La Movilidad Intergeneracional del Ingreso en Argentina y Chile: Comparando Resultados y Evaluando Métodos", Cuadernos del CIMBAGE (en prensa).

KIM, H. (1996). "Trade-Offs between Military Spending, Quality of Life and Economic Growth", Comparative Economic Studies 38 (4), pp. 69-84.

KNIGHT, M., N. LOAYZAN y D. VILLANUEVA (1996). “The Peace Dividend: Military Spending Cuts and Economic Growth", International Monetary Fund Staff Papers 43 (1), pp. 1-37.

KRÜGER, N. (2012). "La segmentación educativa argentina: reflexiones desde una perspectiva micro y macrosocial", Páginas de Educación 5 (1), pp. 137-156.

LILLARD, L. y M. KILBURN (1995). "Intergenerational earnings links: sons and daughters", Corporation Provides Objective Research Service, RAND Working Paper Series $\mathrm{N}^{\circ} 17$.

LILLARD, L. y R. WILLIS (1994). "Intergenerational Educational Mobility: Effects of Family and State in Malaysia", Journal of Human Resources 29 (4), pp. 1126-1166.

MACHIN, S. (2007), "Education Expansion and Intergenerational Mobility in Britain”, en L. Woessman y P. Peterson, Schools and the Equal Opportunity Problem, MIT Press, Cambridge, pp. 29-50.

MAYER, S.E. (2002). "The Influence of Parental Income on Children's Outcomes: A Review Report to the New Zealand", Ministry of Social Development. 17 de noviembre de 2013, <https://www.msd. govt.nz/documents/about-msd-and-our-work/publications-resources/research/influence-parentalincome/influence-of-parental-income.pdf. $>$.

MAYER, S.E. y L.M. LOPOO (2008). "Government Spending and Intergenerational Mobility", Journal of Public Economics 92 (1-2), pp. 139-158.

MAZUMDER, B. (2005). "Fortunate Sons: New Estimates of Intergenerational Mobility in the United States Using Social Security Earnings Data", The Review of Economics and Statistics 87 (2), pp. 235-255.

MÜLLER, A. y S. DE RACO (2010). "Impacto Fiscal de las Transacciones del Gobierno Federal. Una Evaluación para 2003-2008", Centro de Estudios de la Situación y Perspectivas de la Argentina, Universidad de Buenos Aires, Documento de trabajo No 15.17 de noviembre de 2013. <http:// home.econ.uba.ar/economicas/sites/default/files/cespa15_1.pdf.>.

MULLIGAN, C. (1997). Parental Priorities and Economic Inequality, University of Chicago Press, Chicago.

NICOLETTI, C. (2008). "Multiple Sample Selection in the Estimation of Intergenerational Occupational Mobility”, Institute for social \& Economic Research (ISER), University of Essex, Working paper $\mathrm{N}^{\circ} 20.15$ de mayo de 2009, <https://www.iser.essex.ac.uk/research/publications/working-papers/ iser/2008-20>.

NICOLETTI, C. y M. FRANCESCONI (2006). "Intergenerational mobility and sample selection in short panels", Journal of Applied Econometrics 21 (8), pp. 1265-1293.

NUÑEZ, J. y C. RISCO (2004). "Movilidad Intergeneracional de Ingresos en un País en Desarrollo: El Caso De Chile", Departamento de Economía, Universidad de Chile, Working Paper No 210. 1 de mayo de 2008, <http://www.econ.uchile.cl/uploads/publicacion/1e400f38-ebad-4a8f-927113929535eb48.pdf.>.

NUÑEZ, J. y L. MIRANDA (2011). "Intergenerational income and educational mobility in urban Chile", Estudios de Economía 38 (1), pp. 195-221. 
PAQUEO, V. y K. LEE (2000). "Protecting the Poor and Improving Investment in their Human Capital", en M. A. Cervantes-Miguel, T. Gomez y C. Zavaleta, Poor people in a rich country. A Poverty Report for Argentina, The World Bank, Washington D.C., pp. 144-196.

PAYNE, J. y K. ROSS (1992). "Defense Spending and the Macroeconomy", Defense Economics 3 (2), pp. 161-168.

PEKKARINEN, T., R. UUSITALO y S. KERR (2009). "School Tracking and Intergenerational Income Mobility: Evidence from the Finnish Comprehensive School Reform", Journal of Public Economics 93 (7-8), pp. 965-973.

PORTO, A. y P. SANGUINETTI (2001). "Political Determinants of Intergovernmental Grants: Evidence from Argentina", Economics and Politics 13 (3), pp. 237-253.

RUSSETT, M. (1969). “Who Pays for Defense?”, American Political Science Review 63 (2), pp. 412-426.

SANCHEZ HUGALDE, A. (2004). "Movilidad Intergeneracional de Ingresos y Educativa en España (1980-90)", Instituto de Economía de Barcelona, Document de treball № 1.20 de junio de 2012, <http://www.ieb.ub.edu/aplicacio/fitxers/139614ART146.pdf>.

SANGUINETTI, J. y M. TOMMASI (2001). "Una Propuesta de Reforma Integral del Sistema Fiscal Federal", Centro de Estudios para el Desarrollo Institucional, Mimeo.

SENDON, M.A. (2005). "Las Trayectorias de los Egresados de la Escuela Media en una Sociedad Mutada", Revista Mexicana de Investigación Educativa 10 (24), pp. 191-219.

SOLON, G. (1992). "Intergenerational Income Mobility in the United States", The American Economic Review 82 (3), pp. 393-408.

SOLON, G. (2004). "A Model of Intergenerational Mobility Variation over Time and Place", en M. Corak, Generational Income Mobility in North America and Europe, Cambridge University Press, Cambridge, pp. 38-47.

YILDIRIM, J. y S. SEZGIN (2002). "Defense, Education and Health Expenditures in Turkey”, Journal of Peace Research 39 (5), pp. 569-580.

ZAPATA, J.A., A.O. BERTEA y T.B. ITURRE (2000). "Sistema de Supervisión Multilateral: para un Federalismo con Responsabilidad Fiscal”, Reunión anual 2000 de ABA y Expobank. 17 de noviembre de 2013, <http://www.municipios.unq.edu.ar/modules/mislibros/archivos/SM1261.pdf.>. 


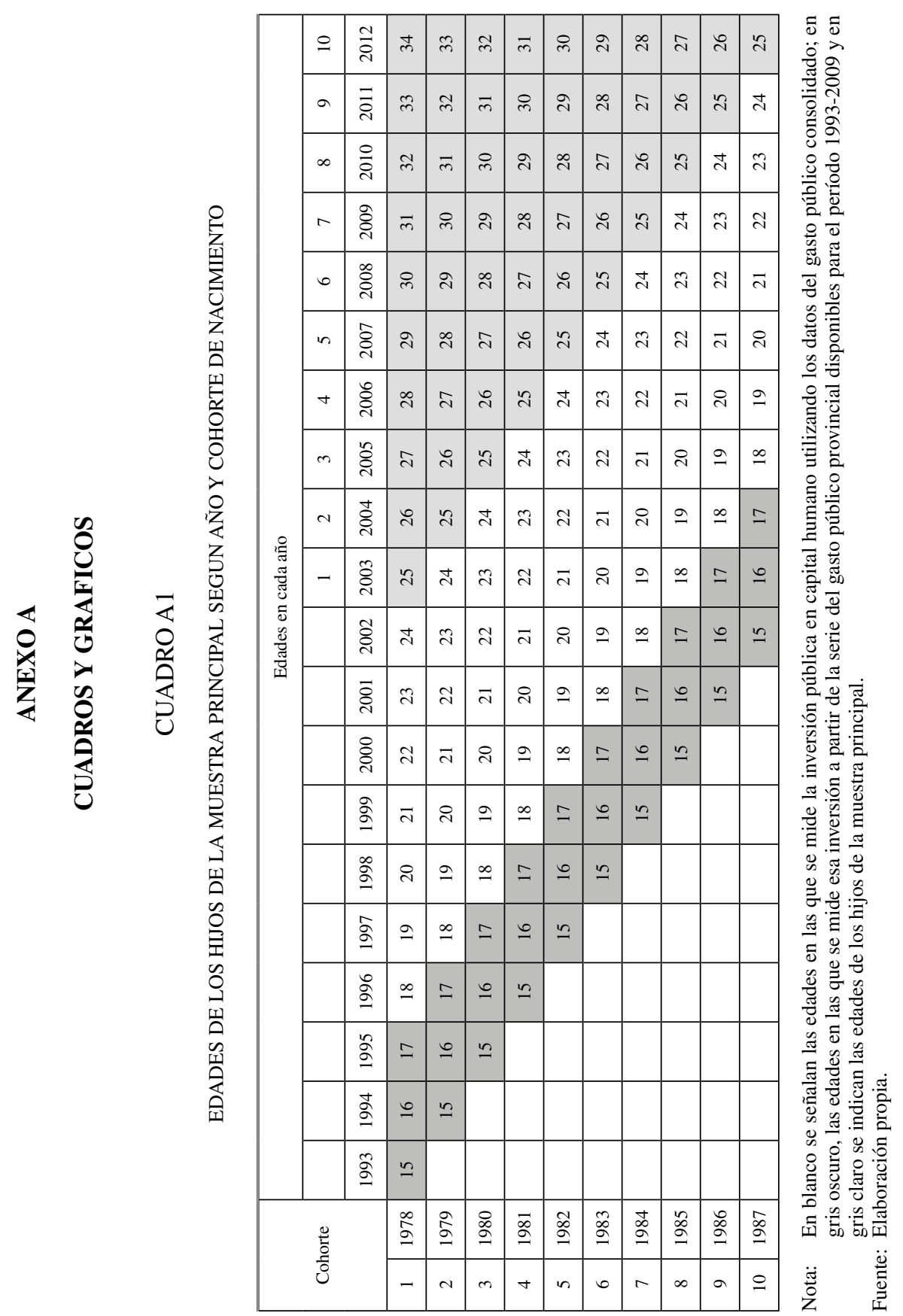




\section{CUADRO A2}

\section{BRECHAS EN LA MOVILIDAD INTERGENERACIONAL EDUCATIVA SEGUN NIVEL DE GASTO PUBLICO}

\begin{tabular}{|l|c|c|c|}
\hline \multicolumn{1}{|c|}{ Variables de interés } & $\begin{array}{c}\text { Nivel de } \\
\text { gasto bajo }\end{array}$ & $\begin{array}{c}\text { Nivel de } \\
\text { gasto medio }\end{array}$ & $\begin{array}{c}\text { Nivel de } \\
\text { gasto alto }\end{array}$ \\
\hline $\begin{array}{l}\text { Educación del padre } \times \text { Nivel } \\
\text { educativo bajo de la madre }\end{array}$ & $0,220^{* * *}$ & $0,193^{* * *}$ & $0,150^{* * *}$ \\
Educación del padre & $(0,153-0,287)$ & $(0,122-0,265)$ & $(0,093-0,206)$ \\
& $0,129^{* * *}$ & $0,139^{* *}$ & $0,128^{* * *}$ \\
$\begin{array}{l}\text { Nivel educativo bajo de la } \\
\text { madre }\end{array}$ & $(0,075-0,182)$ & $(0,029-0,249)$ & $(0,062-0,194)$ \\
& $-4,026^{* * *}$ & $-3,867 * * *$ & $-3,153^{* * *}$ \\
& $(-4,979--3,073)$ & $(-5,212--2,522)$ & $(-3,743--2,563)$ \\
\hline
\end{tabular}

Nota: $\quad * * * p$-value $<0,01, * * p$-value $<0,05, *$ p-value $<0,1$. Entre paréntesis se reportan los intervalos de confianza al $95 \%$ computados a partir de errores estándares agrupados a nivel provincial. Ver en el Cuadro 3 la descripción de las variables explicativas incluidas en el modelo estimado.

Fuente: Elaboración propia sobre la base de varias fuentes de información. Ver la sección de datos para más detalles.

\section{CUADRO A3}

\section{EFECTO DE LAS CATEGORIAS DEL GASTO PUBLICO SOCIAL PROVINCIAL PER CAPITA SOBRE LA ELASTICIDAD INTERGENERACIONAL DEL INGRESO}

\begin{tabular}{|c|c|c|c|c|}
\hline \multirow{2}{*}{ Categorías GPPpc } & \multicolumn{2}{|c|}{ Modelo intergeneracional del ingreso } & \multicolumn{2}{|c|}{ Modelo intergeneracional educativo } \\
\hline & Variables de interés & Coeficientes & Variables de interés & Coeficientes \\
\hline Salud & $\begin{array}{l}\text { Log del ingreso del padre } \\
\text { Log gasto público per cápita } \\
\text { Log del ingreso del padre } \times \\
\text { Log gasto público per cápita }\end{array}$ & $\begin{array}{c}0,863^{* * *} \\
(0,097) \\
0,144 \\
(0,104) \\
-0,046^{* *} \\
(0,020)\end{array}$ & $\begin{array}{l}\text { Educación del padre } \\
\text { Log gasto público per cápita } \\
\text { Educación del padre } \times \\
\text { Log gasto público per cápita }\end{array}$ & $\begin{array}{c}0,732 * * * \\
(0,142) \\
1,230 * \\
(0,621) \\
-0,072 * * \\
(0,029)\end{array}$ \\
\hline Atención médica & $\begin{array}{l}\text { Log del ingreso del padre } \\
\text { Log gasto público per cápita } \\
\text { Log del ingreso del padre } \times \\
\text { Log gasto público per cápita }\end{array}$ & $\begin{array}{l}0,789 * * * \\
(0,078) \\
0,129 \\
(0,089) \\
-0,034 * \\
(0,017)\end{array}$ & $\begin{array}{l}\text { Educación del padre } \\
\text { Log gasto público per cápita } \\
\text { Educación del padre } \times \\
\text { Log gasto público per cápita }\end{array}$ & $\begin{array}{c}0,678^{* * *} \\
(0,082) \\
0,927 * \\
(0,456) \\
-0,067 * * * \\
(0,018)\end{array}$ \\
\hline Obras sociales & $\begin{array}{l}\text { Log del ingreso del padre } \\
\text { Log gasto público per cápita } \\
\text { Log del ingreso del padre } \times \\
\text { Log gasto público per cápita }\end{array}$ & $\begin{array}{l}0,792 * * * \\
(0,133) \\
0,249 \\
(0,159) \\
-0,040 \\
(0,036)\end{array}$ & $\begin{array}{l}\text { Educación del padre } \\
\text { Log gasto público per cápita } \\
\text { Educación del padre } \times \\
\text { Log gasto público per cápita }\end{array}$ & $\begin{array}{l}0,402 * * * \\
(0,084) \\
1,959 * * * \\
(0,582) \\
-0,006 \\
(0,023)\end{array}$ \\
\hline
\end{tabular}


Cuadro A3 (continuación)

\begin{tabular}{|c|c|c|c|c|}
\hline \multirow{2}{*}{ Categorías GPPpc } & \multicolumn{2}{|c|}{ Modelo intergeneracional del ingreso } & \multicolumn{2}{|c|}{ Modelo intergeneracional educativo } \\
\hline & Variables de interés & Coeficientes & Variables de interés & Coeficientes \\
\hline $\begin{array}{l}\text { Promoción y asistencia } \\
\text { social }\end{array}$ & $\begin{array}{l}\text { Log del ingreso del padre } \\
\text { Log gasto público per cápita } \\
\text { Log del ingreso del padre } \times \\
\text { Log gasto público per cápita }\end{array}$ & $\begin{array}{l}1,112 * * * \\
(0,134) \\
0,621 * * * \\
(0,167) \\
-0,130 * * * \\
(0,037)\end{array}$ & $\begin{array}{l}\text { Educación del padre } \\
\text { Log gasto público per cápita } \\
\text { Educación del padre } \times \\
\text { Log gasto público per cápita }\end{array}$ & $\begin{array}{c}0,708 * * * \\
(0,135) \\
0,894 * \\
(0,490) \\
-0,090 * * \\
(0,038)\end{array}$ \\
\hline $\begin{array}{l}\text { Promoción y asistencia } \\
\text { social pública }\end{array}$ & $\begin{array}{l}\text { Log del ingreso del padre } \\
\text { Log gasto público per cápita } \\
\text { Log del ingreso del padre } \times \\
\text { Log gasto público per cápita }\end{array}$ & $\begin{array}{l}1,114 * * * \\
(0,131) \\
0,635^{* * *} \\
(0,168) \\
-0,131 * * * \\
(0,037)\end{array}$ & $\begin{array}{l}\text { Educación del padre } \\
\text { Log gasto público per cápita } \\
\text { Educación del padre } \times \\
\text { Log gasto público per cápita }\end{array}$ & $\begin{array}{c}0,716^{* * *} \\
(0,126) \\
0,961^{*} \\
(0,478) \\
-0,093^{* *} \\
(0,036)\end{array}$ \\
\hline Educación y cultura & $\begin{array}{l}\text { Log del ingreso del padre } \\
\text { Log gasto público per cápita } \\
\text { Log del ingreso del padre } \times \\
\text { Log gasto público per cápita }\end{array}$ & $\begin{array}{l}1,404 * * * \\
(0,248) \\
0,622 * * \\
(0,233) \\
-0,141 * * * \\
(0,047)\end{array}$ & $\begin{array}{l}\text { Educación del padre } \\
\text { Log gasto público per cápita } \\
\text { Educación del padre } \times \\
\text { Log gasto público per cápita }\end{array}$ & $\begin{array}{c}0,820^{* * *} \\
(0,226) \\
1,043^{*} \\
(0,581) \\
-0,081^{*} \\
(0,043)\end{array}$ \\
\hline Educación básica & $\begin{array}{l}\text { Log del ingreso del padre } \\
\text { Log gasto público per cápita } \\
\text { Log del ingreso del padre } \times \\
\text { Log gasto público per cápita }\end{array}$ & $\begin{array}{c}1,115^{* * *} \\
(0,264) \\
0,370 \\
(0,265) \\
-0,091^{*} \\
(0,053)\end{array}$ & $\begin{array}{l}\text { Educación del padre } \\
\text { Log gasto público per cápita } \\
\text { Educación del padre } \times \\
\text { Log gasto público per cápita }\end{array}$ & $\begin{array}{c}0,567 * * * \\
(0,157) \\
0,658 \\
(0,491) \\
-0,036 \\
(0,032)\end{array}$ \\
\hline $\begin{array}{l}\text { Educación superior y } \\
\text { universitaria }\end{array}$ & $\begin{array}{l}\text { Log del ingreso del padre } \\
\text { Log gasto público per cápita } \\
\text { Log del ingreso del padre } \times \\
\text { Log gasto público per cápita }\end{array}$ & $\begin{array}{c}0,863 * * * \\
(0,082) \\
0,446 * * \\
(0,161) \\
-0,084 * * * \\
(0,029)\end{array}$ & $\begin{array}{l}\text { Educación del padre } \\
\text { Log gasto público per cápita } \\
\text { Educación del padre } \times \\
\text { Log gasto público per cápita }\end{array}$ & $\begin{array}{c}0,490 * * * \\
(0,082) \\
0,485 \\
(0,425) \\
-0,041 \\
(0,032)\end{array}$ \\
\hline Vivienda y urbanismo & $\begin{array}{l}\text { Log del ingreso del padre } \\
\text { Log gasto público per cápita } \\
\text { Log del ingreso del padre } \times \\
\text { Log gasto público per cápita }\end{array}$ & $\begin{array}{c}0,503^{* * *} \\
(0,063) \\
-0,149 \\
(0,138) \\
0,044^{*} \\
(0,022)\end{array}$ & $\begin{array}{l}\text { Educación del padre } \\
\text { Log gasto público per cápita } \\
\text { Educación del padre } \times \\
\text { Log gasto público per cápita }\end{array}$ & $\begin{array}{c}0,329 * * * \\
(0,039) \\
0,278 \\
(0,376) \\
0,017 \\
(0,013)\end{array}$ \\
\hline Agua y alcantarillado & $\begin{array}{l}\text { Log del ingreso del padre } \\
\text { Log gasto público per cápita } \\
\text { Log del ingreso del padre } \times \\
\text { Log gasto público per cápita }\end{array}$ & $\begin{array}{c}0,596 * * * \\
(0,061) \\
-0,097 \\
(0,144) \\
0,021 \\
(0,028)\end{array}$ & $\begin{array}{l}\text { Educación del padre } \\
\text { Log gasto público per cápita } \\
\text { Educación del padre } \times \\
\text { Log gasto público per cápita }\end{array}$ & $\begin{array}{c}0,347 * * * \\
(0,029) \\
-0,246 * * \\
(0,109) \\
0,017 \\
(0,010)\end{array}$ \\
\hline
\end{tabular}

Nota: $\quad * * * p$-value $<0,01, * * p$-value $<0,05, * p$-value $<0,1$. Entre paréntesis se reportan los errores estándares agrupados a nivel provincial.

Fuente: Elaboración propia sobre la base de varias fuentes de información. Ver la sección de datos para más detalles. 


\section{GRAFICO A1}

PARTICIPACION PROMEDIO DEL GASTO PUBLICO PROVINCIAL EN EL GASTO PUBLICO CONSOLIDADO TOTAL Y SOCIAL SEGUN CATEGORIAS. 1998-2008

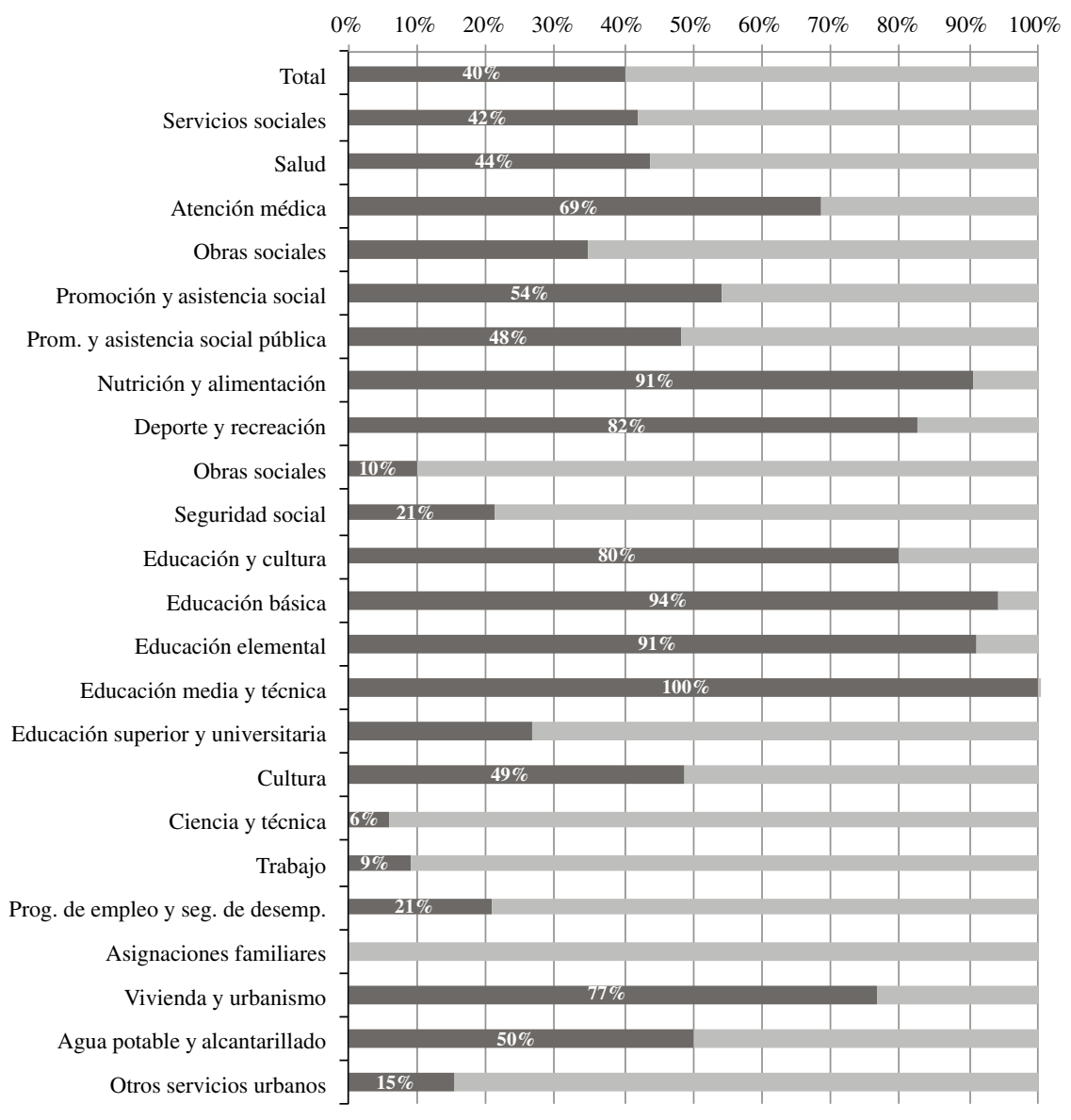

$\%$ del GPC ejecutado por las provincias $\%$ del GPC ejecutado por la nación y muncipios

Fuente: Elaboración propia sobre la base de DAGPyPS y MECON. 


\section{ANEXO B \\ BREVE DESCRIPCION DE LOS DATOS SOBRE GASTO PUBLICO Y DE LOS INDICADORES PROVINCIALES UTILIZADOS EN EL ANALISIS EMPIRICO}

A continuación se describen brevemente los datos del gasto público consolidado así como las series de los indicadores provinciales utilizados como variables de control en los modelos estimados. Respecto del gasto público consolidado se debe señalar que la consolidación es un método que permite mostrar las estadísticas de un conjunto de unidades (el gobierno nacional, provincial y municipal, en este caso) como si fuesen una sola, ya que elimina las transacciones y posiciones de saldo recíprocas entre las unidades (FMI, 2001). La elaboración de cuentas consolidadas involucra tres fases: homogeneización, eliminación y agregación. Homogeneizar la información implica abordar aspectos temporales, valorativos y terminológicos -como las clasificaciones presupuestarias- vinculados con las transacciones que realizan las unidades a consolidar. Por su parte, la segunda etapa comprende la eliminación de las transferencias que realiza un nivel de gobierno hacia otro, para evitar la doble contabilización. Por último, la agregación consiste en sumar las partidas, homogeneizadas y netas de transacciones (Jiménez, 2002). Los principales criterios metodológicos que emplea la Dirección de Análisis del Gasto Público y Programas Sociales (DAGPyPS) para consolidar el gasto son: i) imputar las erogaciones en el nivel de gobierno ejecutor y ii) utilizar la etapa presupuestaria "devengado". El primer criterio hace referencia a que el gasto se imputa en el nivel de gobierno que lo ejecuta y no en el que lo financia. Por tanto, para evitar duplicaciones las transferencias de fondos de la nación a provincias y municipios, así como la de provincias a municipios, se descuentan del nivel del gobierno financiador y son incluidas en el ejecutor. El criterio de base devengado alude al momento de registro de las transacciones incluidas en la consolidación. Es decir, los eventos económicos se registran en el período en que ocurren, independientemente de que se haya efectuado o de que esté pendiente el cobro o el pago efectivo ${ }^{42}$. Por otra parte, la distribución geográfica del GPC se realizó tomando como unidad de análisis el nivel de gobierno provincial, incluyendo la Ciudad de Buenos Aires. De este modo, sin tomar en cuenta las externalidades interjurisdiccionales, la distribución geográfica del GPC implica repartir entre las provincias las erogaciones, sujetas a consolidación, del gobierno nacional. El criterio utilizado para realizar la distribución geográfica del GPC es el criterio del beneficio. Es decir, se asigna el GPC según el lugar de residencia de los beneficiarios de las acciones del Estado. El procedimiento implementado para realizar esta distribución del GPC consiste en los siguientes pasos:

42 Para mayor detalle sobre la metodología de consolidación del gasto público del sector público no financiero, ver DAGPyPS (2011). 
1. Análisis de los objetivos del programa presupuestario.

2. Imputación directa según ubicación geográfica de los beneficiarios a partir de la información obtenida por:

a. Consulta a la unidad ejecutora acerca de información geográfica de las erogaciones vinculadas al programa que se contrasta con la información por ubicación geográfica del Sistema Integrado de Información Financiera (SIDIF). Si coincide se mantiene la distribución original del programa y si no coincide se modifica la distribución de acuerdo con la información provista por la unidad ejecutora del programa.

b. Consulta en la Cuenta Inversión (a) y por medio de las órdenes de pago libradas por la Tesorería General de la Nación (b) en caso de no obtener información de la unidad ejecutora.

3. Imputación indirecta a partir de distribuidores geográficos, si no se obtiene información concluyente en (a) y (b), como una aproximación de la distribución efectiva del gasto, a base de indicadores sectoriales y a los objetivos del programa presupuestario.

Por otra parte se utilizaron las series históricas de los siguientes indicadores provinciales como variables de control:

- Los recursos tributarios provinciales cuya información se obtuvo de la Dirección de Coordinación Fiscal con las provincias del MECON.

- La carga tributaria nacional por jurisdicción (proporción de la recaudación nacional que se obtiene de cada provincia y la Ciudad Autónoma de Buenos Aires) obtenida de los estudios de Zapata, Bertea y Iturre (2000), Sanguinetti y Tommasi (2001) y Müller y De Raco (2010).

- La tasa de pobreza por necesidades básicas insatisfechas (NBI), la tasa de desocupación, el coeficiente de Gini, la tasa de asistencia a cada nivel educativo de la población en el grupo etario objetivo, los años promedio de educación de la PET, la proporción de la población sin cobertura de salud, el porcentaje de la población sin acceso a agua corriente y sin acceso a desagües cloacales por provincia. Todos estos indicadores fueron computados a partir de la EPH.

- La tasa de mortalidad infantil (por mil nacidos vivos) y la tasa de mortalidad total (por mil habitantes) por provincia obtenidas de la Dirección de Estadística e Información de Salud (DEIS) del Ministerio de Salud de la Nación.

- La población total por provincia que se obtuvo de las proyecciones de población realizada por el Instituto Nacional de Estadísticas y Censos (INDEC, 2005).

- La tasa de crecimiento del PBG per cápita de cada provincia computada a partir de la información obtenida de las Direcciones Provinciales de Estadística. 
- El partido político del gobernador de cada provincia en relación con el del presidente al mando, información sistematizada por la Unidad de Información Provincial Integrada (ProvInfo) de la Secretaría de Provincias del Ministerio del Interior y Transporte. La variable construida a partir de esta información indica para cada hijo adulto la proporción de años durante su adolescencia o juventud en los que el gobernador de su provincia fue del mismo partido que el presidente al mando. La inclusión de esta variable como control en el modelo empírico se fundamenta principalmente en la evidencia empírica disponible que revela que más allá de las necesidades y capacidades fiscales locales, otros factores relacionados con las influencias políticas juegan un rol importante en la determinación de las asignaciones horizontales de las transferencias intergubernamentales (Boex y Martinez-Vazquez, 2005; Porto y Sanguinetti, 2001, Atlas et al., 1995). 